Check for updates

Cite this: RSC Adv., 2018, 8, 24541

\title{
Surface modification and pattern formation by nucleobases and their coordination complexes
}

\author{
R. Kamal Saravanan, ${ }^{a}$ Ilesha Avasthi, ${ }^{a}$ Rajneesh Kumar Prajapati ${ }^{\text {ab }}$ \\ and Sandeep Verma (DD *ab
}

This review presents recent progress concerning the organization of nucleobases on highly ordered pyrolytic graphite (HOPG), mica, $\mathrm{Cu}(110)$ and $\mathrm{Au}(111)$ surfaces, followed by their studies using microscopy methods such as atomic force microscopy (AFM), scanning tunneling microscopy (STM) and transmission electron microscopy (TEM). Interesting research prospects related to surface patterning by nucleobases, nucleobase-functionalized carbon nanotubes (CNTs) and metal-nucleobase coordination polymers are also discussed, which offer a wide array of functional molecules for advanced applications. Nucleobases and their analogs are able to invoke non-covalent interactions such as $\pi-\pi$ stacking and hydrogen bonding, and possess the required framework to coordinate metal ions, giving rise to fascinating supramolecular architectures. The latter could be transferred to conductive substrates, such as HOPG and gold, for assessment by high-end tunneling microscopy under various conditions. Clear understanding of the principles governing nucleobase self-assembly and metal ion complexation, and precise control over generation of functional architectures, might lead to custom assemblies for targeted nanotechnological and nanomaterial applications.

Received 7th May 2018

Accepted 26th June 2018

DOI: $10.1039 / \mathrm{c} 8 \mathrm{ra0} 9303 \mathrm{~h}$

rsc.li/rsc-advances different metallic and non-metallic substrates. The inherent hydrogen-bonding ability of nucleobases has also been exploited efficiently to get desired morphologies and nanostructures on surfaces. These supramolecular assemblies could be tuned further by chemical derivatization of nucleobases to allow for stable deposition. Also, the presence of heteroatoms in the core skeleton of nucleobases allows metal ions to interact, in order to achieve various binding patterns on the surface. The choice of substituent, metal salt used for complexation, solvent and substrate is critical for surface patterning. ${ }^{\mathbf{4 4 , 4 5}}$

This review focuses on recent advancements in an exciting area of surface modifications by nucleobases, which has applications in many nanotechnological applications. Nucleobases are useful building blocks, modulators or templates for nanomaterial synthesis and our ability to further fine-tune surfacepatterning could provide entry to novel applications in functional materials science. ${ }^{\mathbf{4 5 - 5 1 , 7 4 , 7 7}}$ Here, subsequent sections describe the surface patterns of unmodified nucleobases, their derivatives, metal-complexes and their functionalized forms. Considerable attention has been invested toward patterning and high-resolution imaging of custom surfaces. ${ }^{452-61,105}$ This review exclusively focuses on fundamental and biologically important five canonical nucleobases, namely adenine, guanine, thymine, cytosine and uracil, surface morphologies created by them alone, followed by coadsorption with peptides, metal-nucleobase complexes and nucleobase-modified carbon nanotubes (CNTs).
${ }^{a}$ Department of Chemistry, Indian Institute of Technology Kanpur, Kanpur, 208016, UP, India.E-mail:sverma@iitk.ac.in

${ }^{b}$ Centre for Nanoscience, Indian Institute of Technology Kanpur, Kanpur 208016, UP, India 

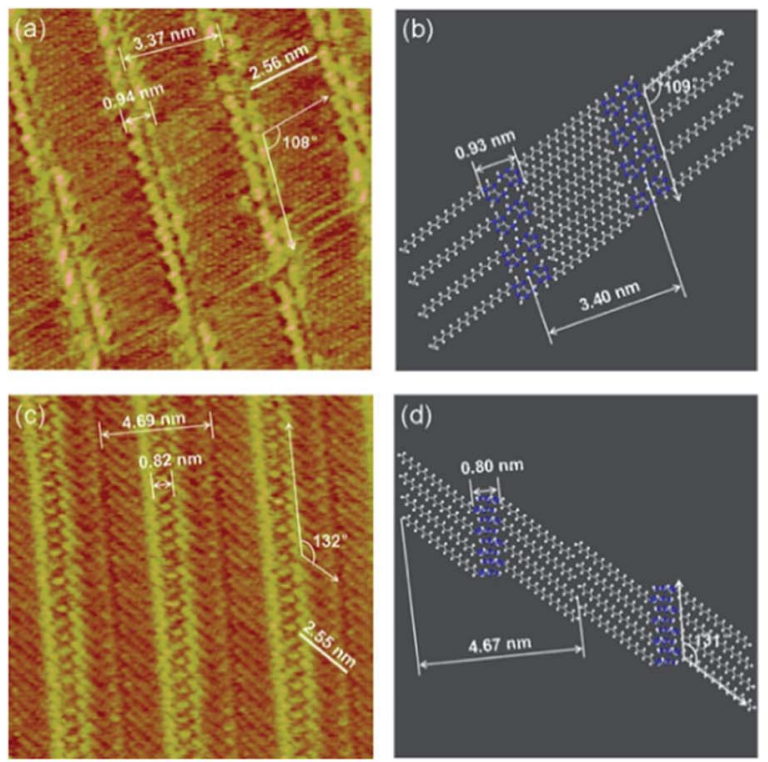

(e)<smiles>CCn1cnc2c(N)ncnc21</smiles>

Fig. 1 (a) STM image of 9-icosyladenine on HOPG surface; (c) high-resolution STM image of (a); (b) and (d) display model structures with scales relatable to (a) and (c) respectively; (e) structure of 9-icosyladenine. (Reproduced with permission from ref. 62 @ 2013, American Chemical Society).

\section{Surface modification by adenine (A) and its analogs}

Nucleobase chemisorption and surface immobilization are primarily guided by operating dispersion forces. In addition to microscopy analyses, many a times these investigations are also supported by density functional theory (DFT) and post-HartreeFock calculations. For example, the creation of (modified) adenine monolayers has been subjected to classical molecular dynamics (MD) simulations and it is articulated that interaction of adenine with surfaces is closely governed by varying degree of base-base aromatic interactions.

Chi and coworkers illustrated in situ STM imaging of 9-icosyladenine physisorbed on HOPG surface revealing two types of temperature-dependent self-assembled structures: $\alpha$ - and $\beta$ phase (Fig. 1). Formation of these on surface phases was driven by $\mathrm{H}$-bonding or aromatic interactions between nucleobases, which was further augmented by van der Waals interactions operating between proximal alkyl chains. ${ }^{62}$

Similar investigations involving a C22 alkyl chain at adenine N9 position revealed two structural phases on the graphite surface, albeit different compared to the previous example, where the deposition pattern was ascribed to the vacuum conditions used for sample preparation (Fig. 2). These highly resolved images helped conclude that substrate temperature and rate of deposition could influence domination of the $\alpha$ phase. $^{63}$

Ordered growth of adenine epitaxial monolayers on graphite were reported by Allen et al. ${ }^{64}$ Two dimensional (2D) networks of adenine dimers, stabilized by $\mathrm{H}$-bonding interactions, were observed at 1-octanol/graphite interface by STM imaging. ${ }^{65}$ Crystalline nature of 2D films, prepared by molecular-beam deposition method, was established using STM and low
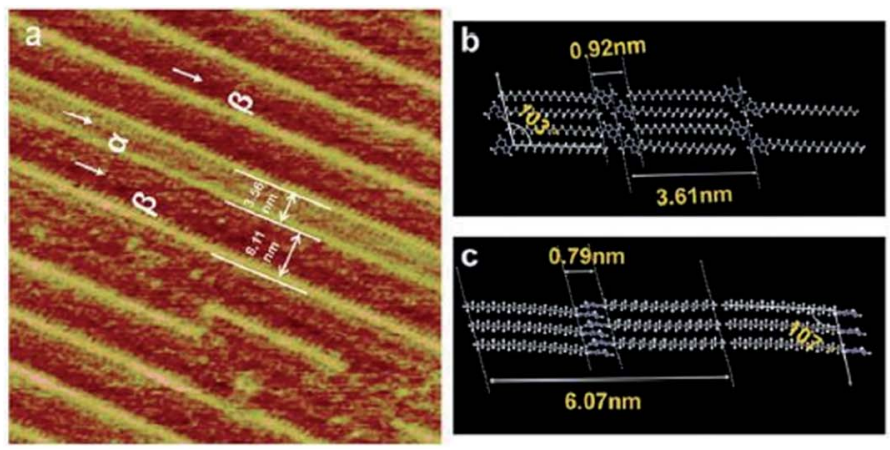<smiles>CCn1cnc2c(N)ncnc21</smiles>

Fig. 2 (a) High-resolution STM image of adenine-C22 on a graphite surface indicating two phases; (b)and (c) comprise of model representations demonstrating intermolecular distances in the two phases; (d) structure of adenine-C22. (Reproduced from ref. 63 with permission from The Royal Society of Chemistry). 
energy electron diffraction (LEED) techniques, ${ }^{\mathbf{6 6}}$ while the coexistence of both homochiral and heterochiral domains was identified with high-resolution STM at 1-octanol/solid interface, at room temperature. ${ }^{67}$

Tao and Shi subjected monolayers of adenine, in aqueous $\mathrm{NaCl}$ solution, to AFM and STM investigations. Both of these techniques suggested that adenine arranged in a hydrogen bonded rectangular lattice on HOPG surface, where molecular packing was independent of the potential, but the electronic states exhibited sensitivity to the substrate potential, as judged by STM. ${ }^{68}$ Notably, the coexistence of homo/hetero chiral domains of self-assembled adenine molecules on various surfaces open up pathways to develop novel surface architectures, which might find useful applications in chiral recognition, chiral separation, heterogeneous catalysis and bioactive surfaces.

Although HOPG is a common substrate for nucleobase organization studies, surfaces such as $\mathrm{Au}(111), \mathrm{Cu}(110)$ and others are also used to address specific questions. For example, adenine exhibited formation of well-ordered 2D islands on $\mathrm{Au}(111)$ revealing two discerning structural possibilities: one of the coexisting phases displayed two adenines per unit cell, while the other presented four adenine molecules, when annealed at $370 \mathrm{~K}$ (Fig. 3).$^{69,70}$ On the contrary, high resolution STM imaging of adenine on $\mathrm{Cu}(110)$, at elevated temperature, revealed $1 \mathrm{D}$ dimeric chains stabilized by hydrogen bonds, in addition to direct bonding between exocyclic $\mathrm{NH}_{2}$ group and the substrate. ${ }^{71}$ Interestingly, flat orientation of adenine is observed on flat $\mathrm{Au}(111)$ and graphite surfaces, whereas non-planar deposition on $\mathrm{Cu}(110)$ could be ascribed to its corrugated surface and favorable interactions of exocyclic amino group with copper.

\section{Surface modification by thymine $(\mathrm{T})$}

Physisorbed thymine at 1-octanol/graphite surface affords zigzag chain-like structure, as viewed through STM, where each thymine is associated with two neighboring molecules, supported by hydrogen bonds. ${ }^{65}$ Interestingly, thymine on $\mathrm{Au}(111)$ substrate leads to randomly oriented $1 \mathrm{D}$ filaments, when viewed at low surface coverage, which gets morphed to 2D island-like growth patterns on increasing the coverage area, supported by weak van der Waals forces. The $2 \mathrm{D}$ islands could be reverted to 1D filaments through STM tip perturbation, suggesting that $2 \mathrm{D}$ islands were loosely held compared to more stable filaments (Fig. 4). ${ }^{72}$

2D island formation by thymine was also observed on $\mathrm{Cu}(111)$ surface. ${ }^{73}$ On the contrary, surface patterning investigations on $\mathrm{Cu}(110)$ surface revealed parallel aligned $1 \mathrm{D}$ chains consisting of oval-shaped structures. These structures were found preferentially oriented along the [001] direction of the substrate. The role of weak dispersion forces in stabilizing thymine molecules was determined by DFT calculations. Desorption studies suggested possible interactions of copper with carbonyl groups as well as with deprotonated N3 of thymine. ${ }^{74}$ Such disassembly of self-organized molecular structures into higher-order superstructures might be helpful in deciphering the nature of intermolecular interactions.

\section{Surface modification by guanine (G) and its analogs}

High resolution studies of guanine self-organization have been carried out on surfaces such as HOPG, Cu(111), and $\mathrm{Au}(111) .^{75}$ These studies have ranged from tunneling microscopy of simple
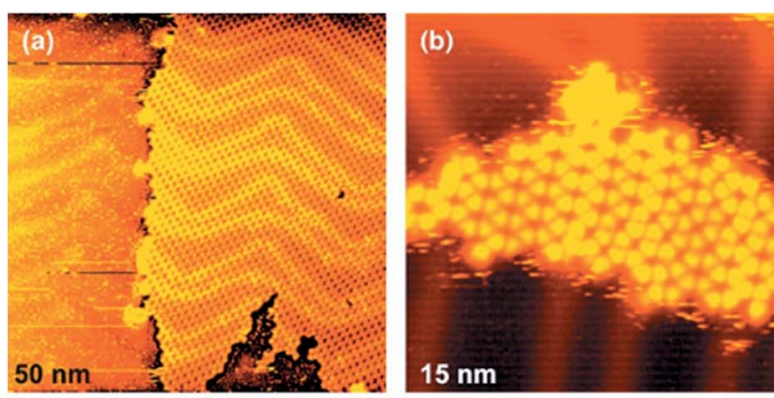

(e)
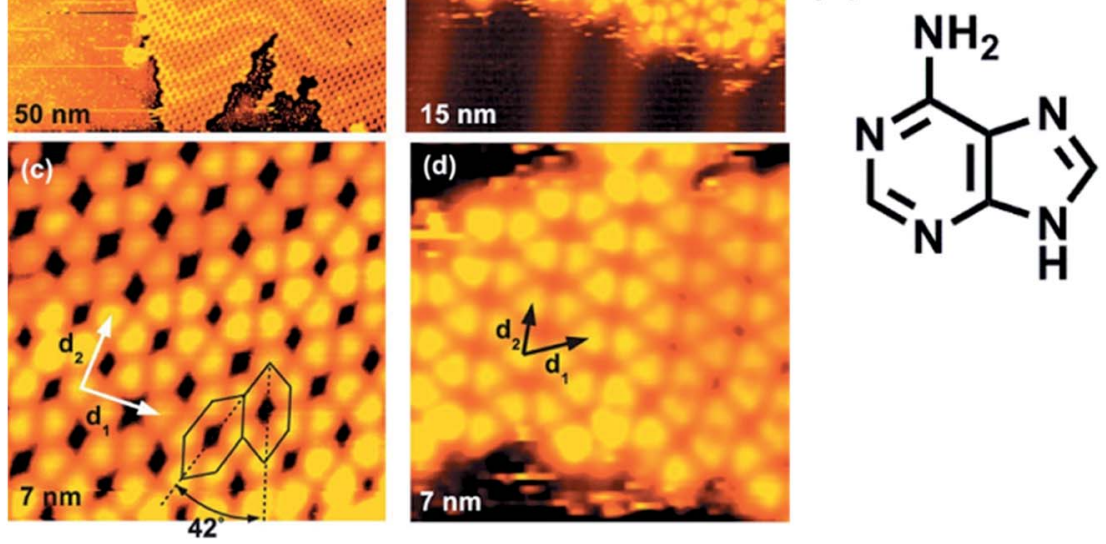

Fig. 3 (a) Ordered 2D structures of adenine on Au(111) as observed through STM; (b) island size of several tens of molecules. Two different structures exist with four [(a) and (c)] and two [(b) and (d)] molecules in the unit cell, respectively. The unit cell is indicated by the corresponding lattice vectors d1 and d2; (e) structure of adenine. (Reproduced with permission from ref. 69 @ 2009 American Institute of Physics). 
guanine monolayers on $\mathrm{HOPG}^{76}$ to self-assembled N9-alkyl derivatives of guanine at 1,2,3-trichlorobenzene/HOPG interface. Self-assembled monolayers of single/dimeric molecules were obtained for $\mathrm{C}_{6}-\mathrm{C}_{10}$ alkyl guanines, while linear ribbonlike structures were observed when alkyl chains were longer than $\mathrm{C}_{12}$ carbons (Fig. 5). These guanine-mediated selfassembled supramolecular architectures could be used to create responsive nanopatterned surfaces, possessing desired motifs with organized electrically/optically active groups for applications in electronics and optical devices.

High resolution STM of guanine on $\mathrm{Au}(111)$ showed appearance of triangularly protruded 2D islands, which on magnification revealed a stable G-quartet like arrangement. Interestingly, an increase in the temperature resulted in appearance of anti-parallel molecular ribbon-like chains, without altering the local environment of guanine (Fig. 6). ${ }^{78}$ Guanine forms close-packed 2D square lattices on $\mathrm{Cu}(111)$ surface, ${ }^{73}$ but an ordered arrangement of guanine revealing 1D worm-like structures was also illustrated by Kawai et. al. ${ }^{79}$ Notably, guanine adsorption was also investigated on a less commonly used Ge(100) surface where detailed STM analyses confirmed that the adsorption occurred via "N(1)-H dissociation through an $\mathrm{O}$ dative bonded structure" mechanism. ${ }^{\mathbf{8 0}}$

\section{Surface modification by cytosine (C)}

There are limited studies pertaining to interaction of cytosine with surfaces. In one study, cytosine was used as a model nonsymmetrical molecule for deposition on $\mathrm{Au}(111)$ surface. STM studies revealed formation of a disordered cytosine network with the identification of three structural possibilities viz. zigzag filaments and five- and six-membered rings, supported by DFT calculations. ${ }^{\mathbf{8 1}}$ In another example, deposition of cytosine on gold surfaces was used to assess the orientation of adsorption and ensuing electronic structure. ${ }^{82}$ It adsorbed in two different ways: the vacuum deposited sample displayed a flat state where interaction through N3 nitrogen dominated, whereas deposition from an aqueous solution involved interaction through N3 and exocyclic amino group. Such studies provide insights into interesting behavior of nucleobase interaction with surfaces and the possibility of studying mediumrange order in amorphous and glassy systems.

\section{Co-adsorption of different nucleobases}

Mixing of adenine and thymine followed by co-deposition led to $2 \mathrm{D}$ nanoassemblies comprised of reverse Hoogsteen $\mathrm{A}-\mathrm{T}-\mathrm{A}-\mathrm{T}$
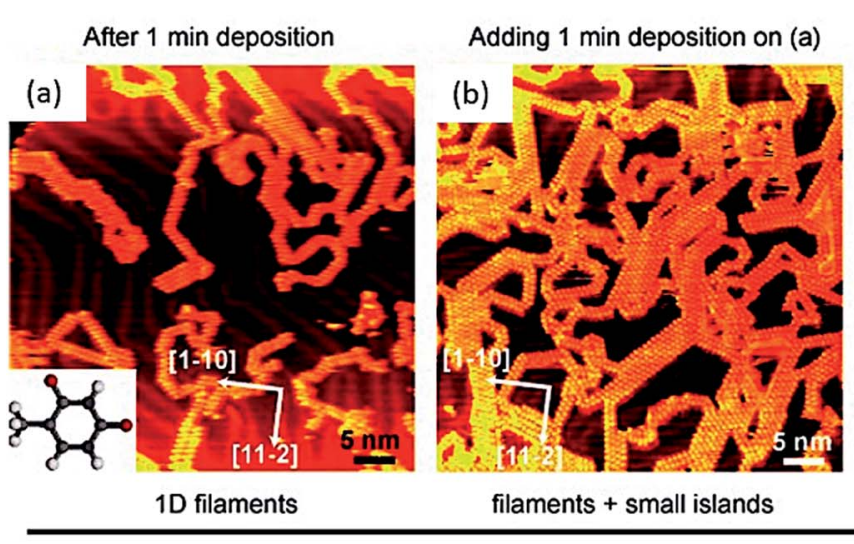

filaments + small islands
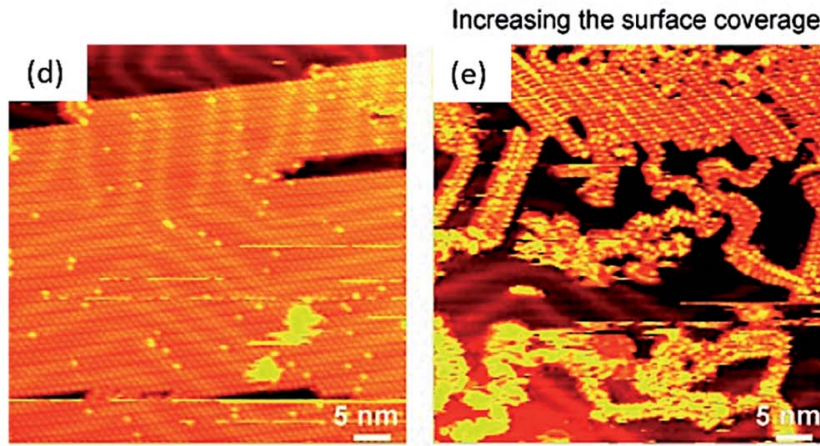

2D large ordered islands

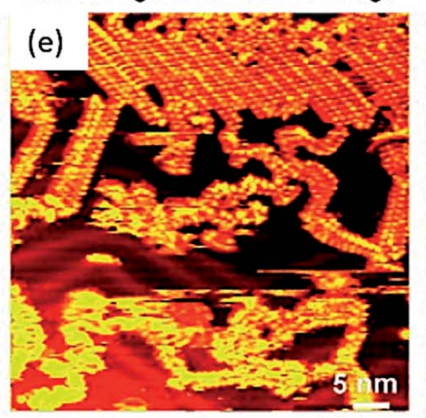

filaments + small islands
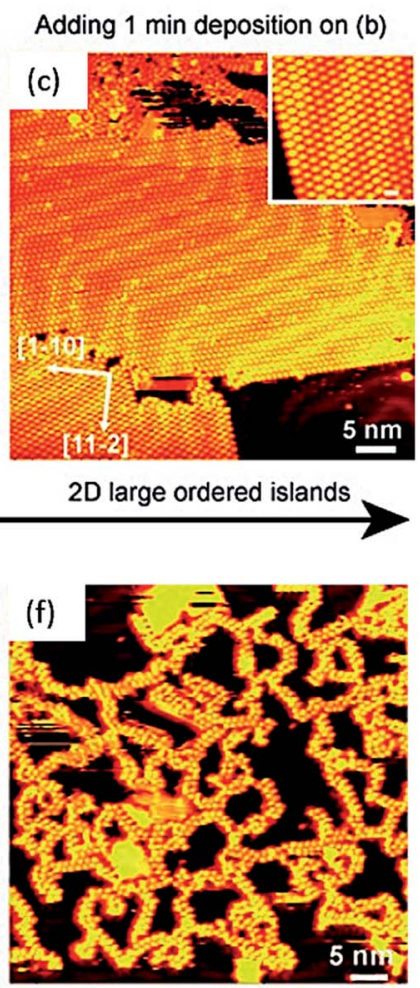

1D filaments

Disassemble 2D islands into filaments by STM tip

Fig. 4 STM images of: (a) 1D thymine filaments on $\mathrm{Au}(111)$ surface at low surface coverage, inset: structure of thymine; (b) 1D filaments and small islands; (c) extended 2D islands. Inset: magnified STM image of 2D island structure. (d-f) Images of STM tip manipulation experiment. (Reproduced with permission from ref. 72 @ 2007 WILEY-VCH Verlag GmbH \& Co. KGaA, Weinheim). 


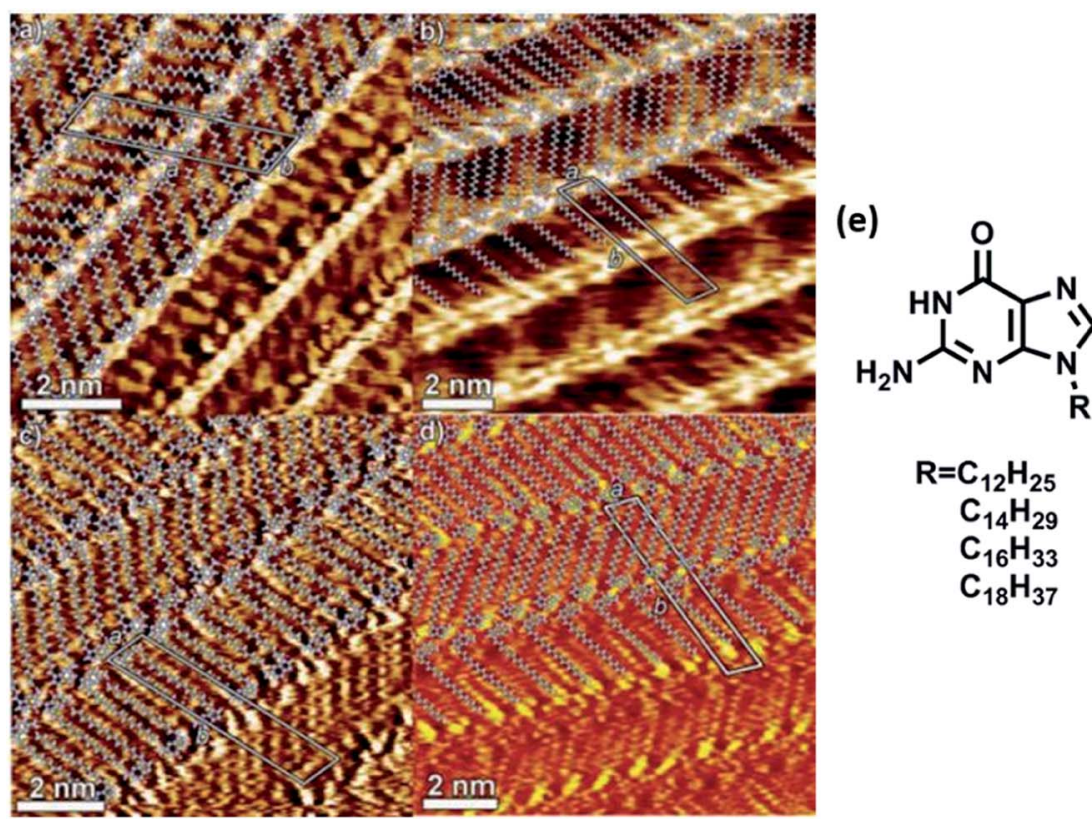

Fig. 5 Hydrogen bonded ribbons obtained from (a) $C_{12}$, (b) $C_{14}$, (c) $C_{16}$, and (d) $C_{18}$ alkyl analogs of guanine by STM imaging; (e) structure of alkyl analogs of guanine. (Reproduced from ref. 77 with permission from The Royal Society of Chemistry).

quartets, separated by homochiral rows of hydrogen bonded adenine dimers, at 1-octanol/HOPG interface. It was suggested that such structures might offer applications in biocompatible nanopatterned surfaces and for targeted drug delivery. ${ }^{65} \mathrm{Co}-$ adsorption of guanine and cytosine also resulted in ordered assemblies at 1-octanol/graphite interface, where one of the phases consisted of hydrogen-bonded guanine-cytosine dimers (Fig. 7). ${ }^{83}$

A novel cyclic 2D supramolecular nanostructure was obtained by co-adsorption of guanine and uracil at 1-octanol/
HOPG interface, which was different compared to homomolecular layers of guanine and uracil. These cyclic structures could be correlated to GU dimers, arranged in a parallel fashion, to reveal patterns of 1D chains in the translated surface monolayer (Fig. 8). ${ }^{84}$

$\mathrm{N}$-Aryl modified cytosine and guanine were co-deposited on $\mathrm{Au}(111)$ surface to afford stable patterns, supported by WatsonCrick hydrogen bonding and van der Waals interactions, which were also validated by DFT calculations. ${ }^{84}$ In another report, Besenbacher and coworkers elaborated structural details of

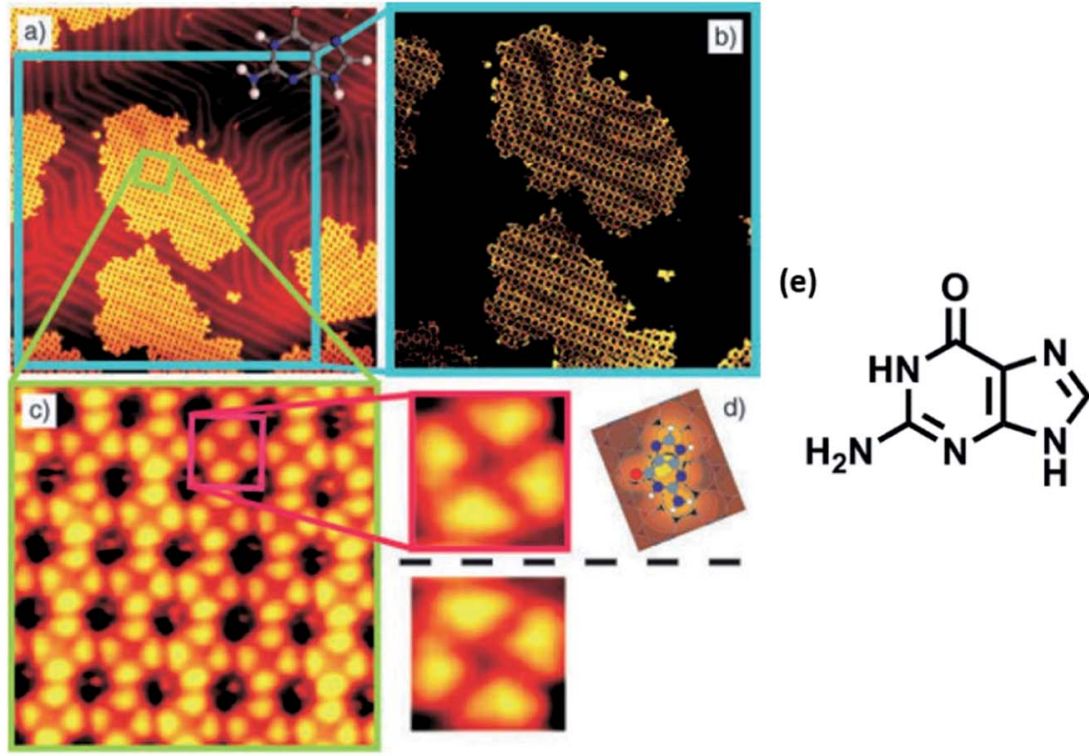

Fig. 6 (a) STM image of self-assembled G islands on Au(111); (b) magnified image of (a); (c) STM image of network of guanine assembly; (d) magnified image of (c); (e) structure of guanine. (Reproduced with permission from ref. 78 ○ 2005 WILEY-VCH Verlag GmbH \& Co. KGaA, Weinheim). 


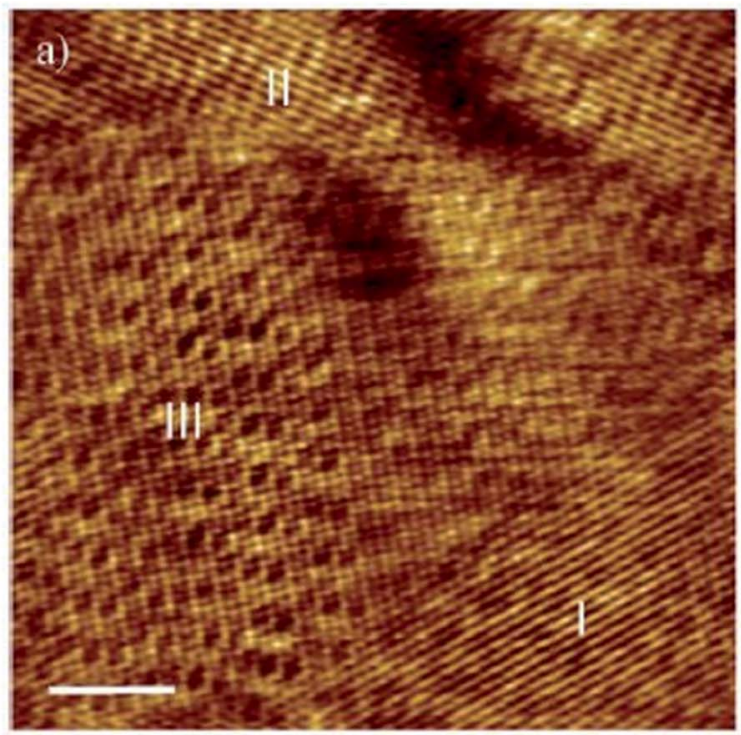

(d)<smiles>Nc1cc[nH]c(=O)n1</smiles>
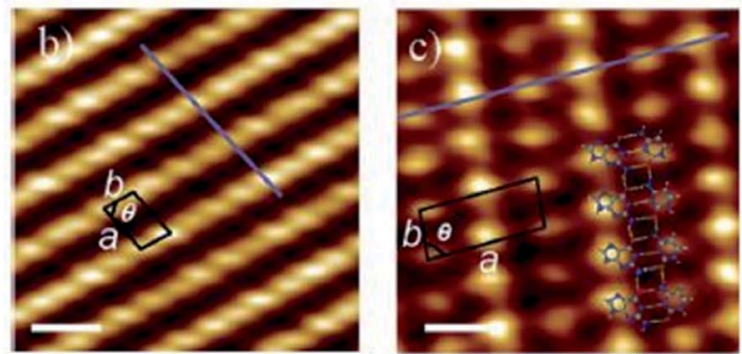<smiles>Nc1nc2[nH]cnc2c(=O)[nH]1</smiles>

Fig. 7 Co-adsorption of cytosine and guanine on HOPG. (a) STM image displaying three distinct domains (labeled I-III), scale bar: 10 nm; (b) zoomed-in view of domain I structure, scale bar: $1 \mathrm{~nm}$; (c) magnified view of domain III revealing an ordered array of high and low protrusions, scale bar: $1 \mathrm{~nm}$; (d) structure of cytosine; (e) structure of guanine. (Reproduced with permission from ref. 83 @2006, American Chemical Society).

cytosine deposition and its co-adsorption with adenine and guanine on $\mathrm{Au}(111)$ substrate. Cytosine alone gave rise to zigzag ring-like arrangement, while with $\mathrm{A}$ or $\mathrm{G}$ on $\mathrm{Au}(111)$ surface revealed a significant shift from homomolecular structure. $\mathrm{G}+\mathrm{C}$ admix afforded ring-like structures, while $\mathrm{A}+\mathrm{C}$ admix formed large islands and zigzag chains on heating, perhaps suggesting a non-interactive nature of $\mathrm{A}$ and $\mathrm{C}$ combination (Fig. 9 and 10). ${ }^{85,86}$

\section{Surface modification by nucleobase functionalised molecules}

Nucleobase terminated, rigid oligo(phenyleneethynylene) molecular rods were deposited on HOPG surface and studied with the help of tunneling microscopy. Adenine-adenine (A-A) dimer displayed a regular arrangement of ordered rectangular patterns, while thymine-thymine (T-T) dimers resulted in an
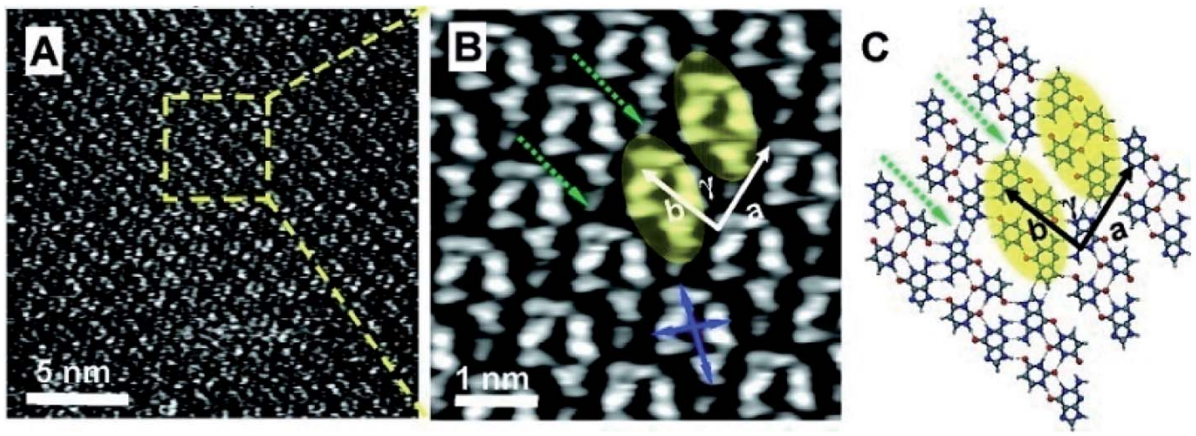

Fig. 8 High-resolution STM images of (a) GU-base pairs; (b) large scale STM image; (c) molecular structure from ab initio calculations. GU-cyclic structures are represented by yellow ovals. (Reproduced with permission from ref. 84 @ 2008, American Chemical Society). 

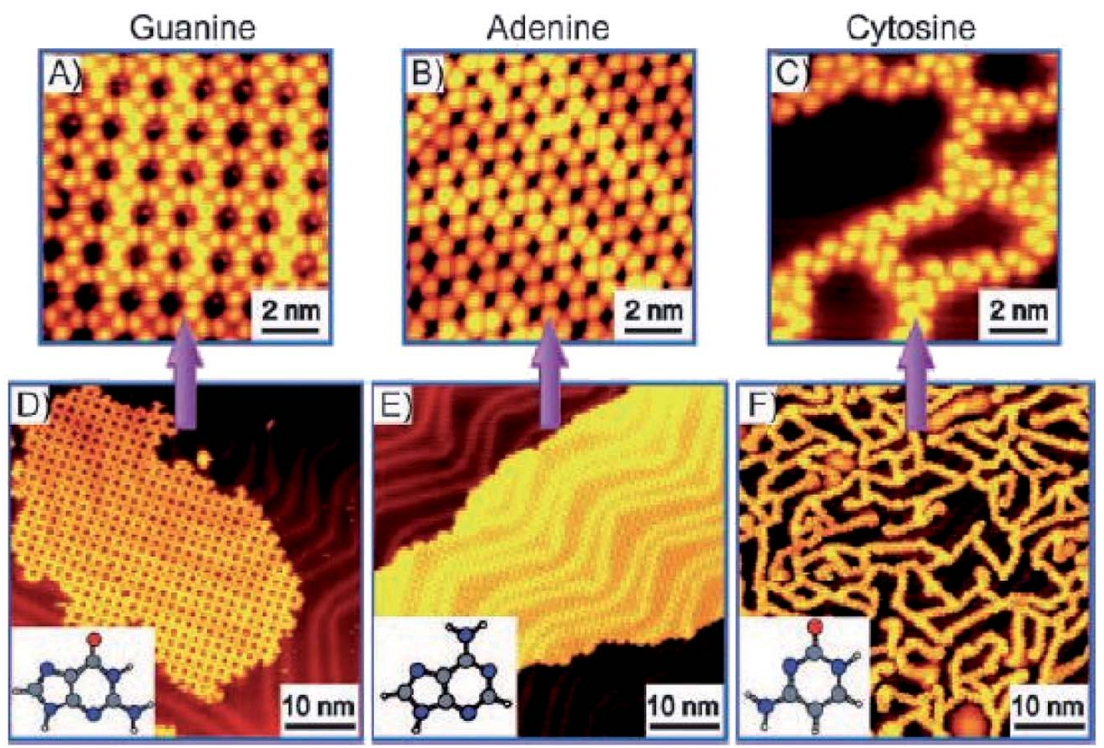

Fig. 9 STM images of guanine ( $A$ and $D$ ) and adenine (B and E) on Au(111) displayed 2D island growth. However, cytosine showed (C and F) 1D filaments consisting of zig-zag branches and ring-like structures. (Reproduced with permission from ref. $86 \odot 2008$ WILEY-VCH Verlag GmbH \& Co. KGaA, Weinheim).

intricate nanostructural pattern. However, an equimolar solution of the two dimers resulted in the structure same as that of homomeric adenine (A-A) system (Fig. 11). ${ }^{87}$

Chiral and achiral oligo-( $p$-phenylenevinylene) (OPV) derivatives, functionalized with a diaminotriazine fragment that has hydrogen-bonding sites complementary to thymine, were probed by STM on 1-octanol/HOPG interface, in the presence of added thymine. High resolution micrographs revealed that rosette-like structures of OPV derivatives transformed to supramolecular diastereomeric patterns due to achiral thymine moiety. This study brings a new dimension to tuning of surface chirality through directed chiral-achiral interactions. ${ }^{88}$

Champness and coworkers reported surface studies with a thymine-modified porphyrin (tetra-TP), which formed uniform self-assembled square lattices on HOPG substrate.

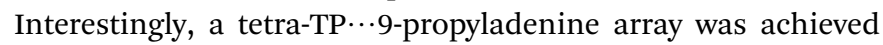
by challenging tetra-TP with 9-propyladenine nucleobase. These studies confirmed concentration dependence and importance
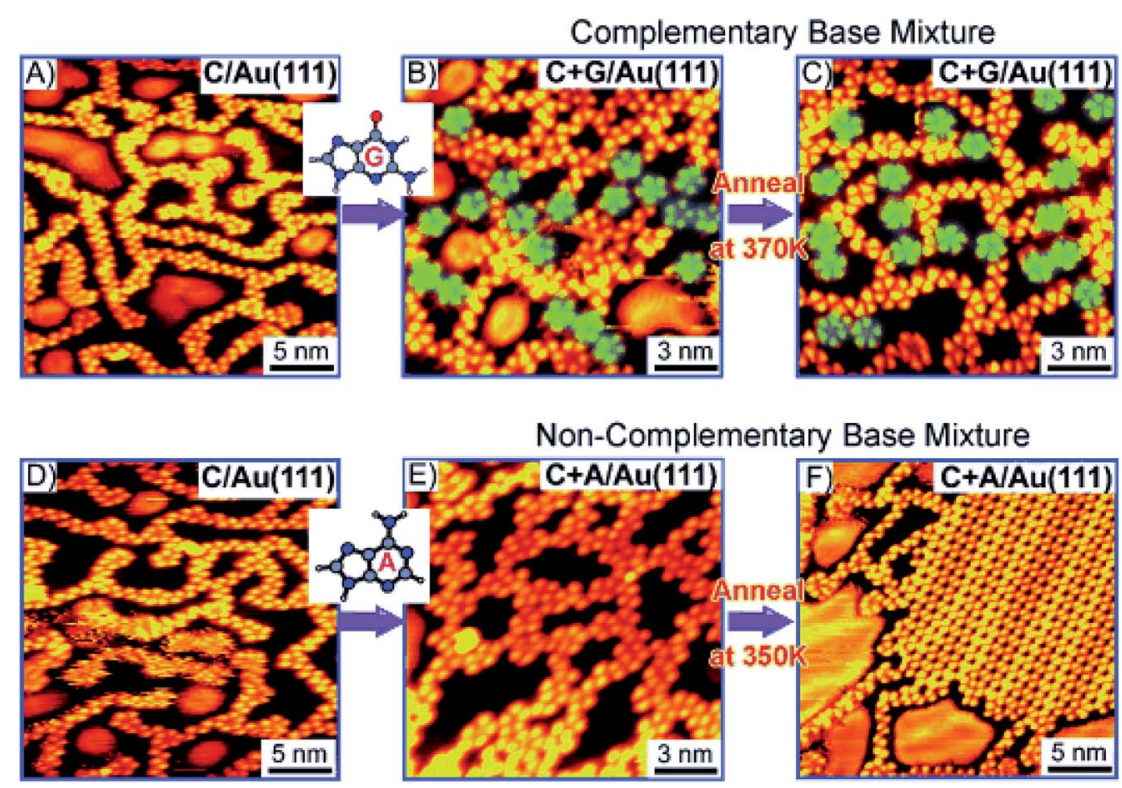

Fig. 10 STM images: ( $A$ and $D$ ) Deposition of $C$ at room temperature; ( $B$ and $C$ ) co-deposition of complementary $C+G$; and ( $E$ and $F$ ) noncomplementary $C+A$ bases; $(B)$ deposition of guanine reveals increase in five-fold rings (indicated by the green shading). $C+G$ and $C+A$ mix on co-deposition (B and E). (Reproduced with permission from ref. 86 @ 2008 WILEY-VCH Verlag GmbH \& Co. KGaA, Weinheim). 


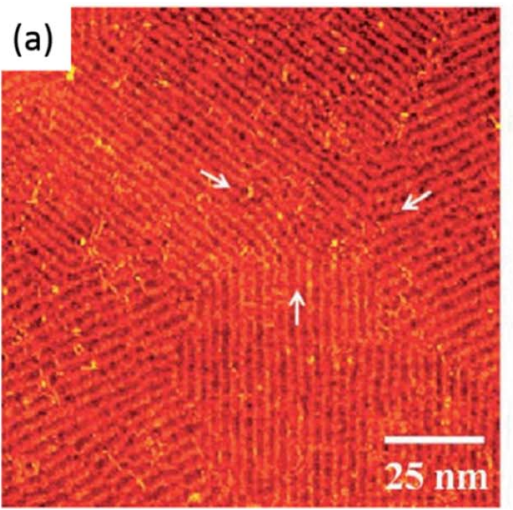

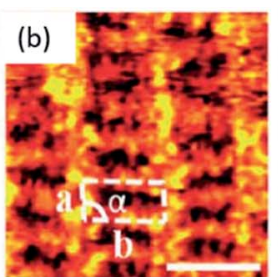

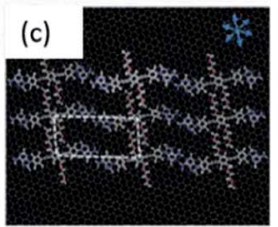

(d)
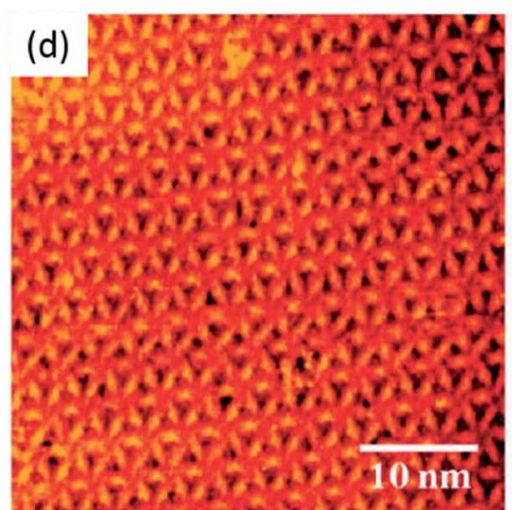
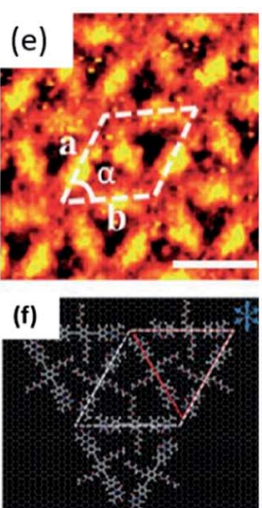

Fig. 11 (a and b) STM images of A-A dimer on HOPG surface. Scale bar in (b) is $3 \mathrm{~nm}$; (c) schematic representation of self-assembly; (d) STM images of T-T dimer on HOPG surface. Scale bar in (e) is $3 \mathrm{~nm}$; (f) schematic representation of supramolecular networks. (Reproduced from ref. 87 with permission from The Royal Society of Chemistry).
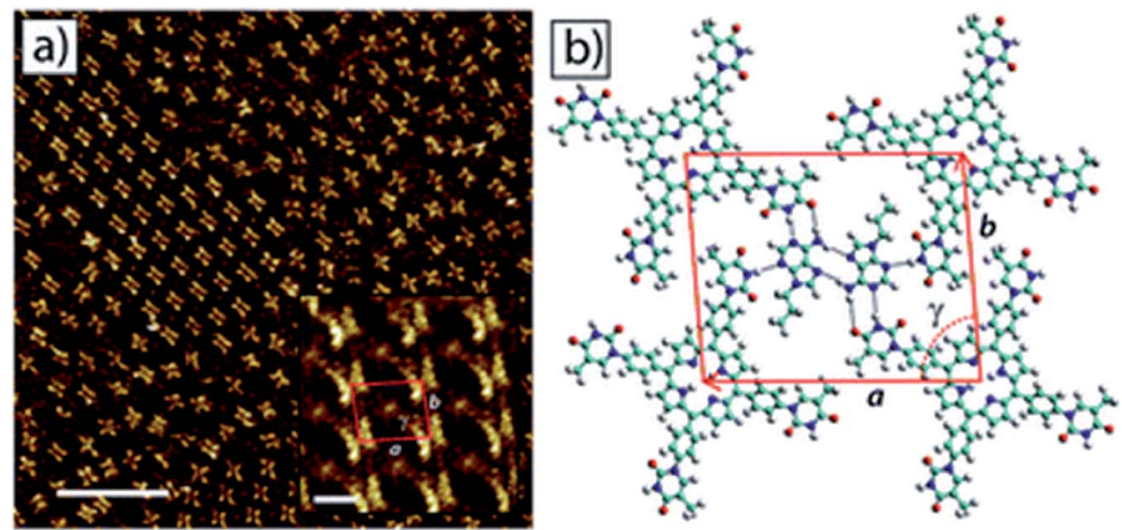

Fig. 12 STM image of (a) self-assembled network of 9-propyladenine and tetra-TP on HOPG surface. Inset: high resolution image of the network. Scale bar $=20 \mathrm{~nm}$, inset: $1.6 \mathrm{~nm}$; (b) molecular model of tetra-TP network. (Reproduced from ref. 89 with permission from The Royal Society of Chemistry).

of molar ratio of individual components, indicating role of multiple factors in directing surface self-assembly (Fig. 12). ${ }^{89}$ Such functionalization is also helpful in crafting of well-tuned surface patterns by modifying the size and shape of supramolecular synthons.

\section{Surface modification by nucleobase functionalised polymers}

Long and coworkers reported copolymerisation of $n$-butylacrylate with novel adenine and thymine acrylate monomers, and
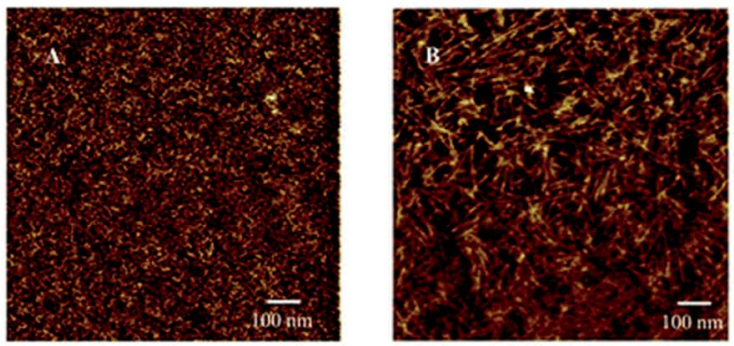

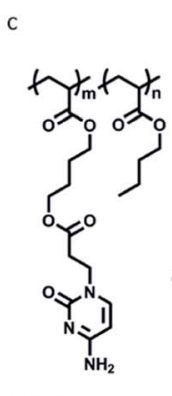

poly(CyA-co-nBA)

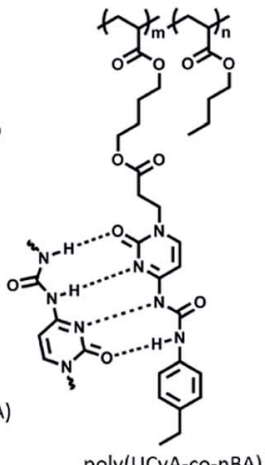

Fig. 13 AFM phase images for (A) poly(CyA-co-nBA); (B) poly(UCyA-co-nBA) films; (C) hydrogen bonding interactions in polymers. (Reproduced from ref. 92 with permission from The Royal Society of Chemistry). 
(a)

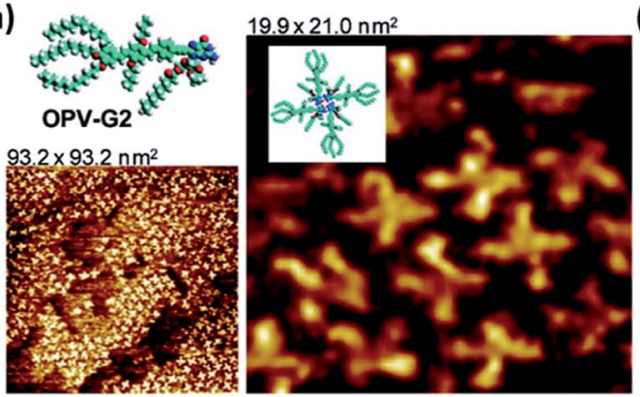

(b)

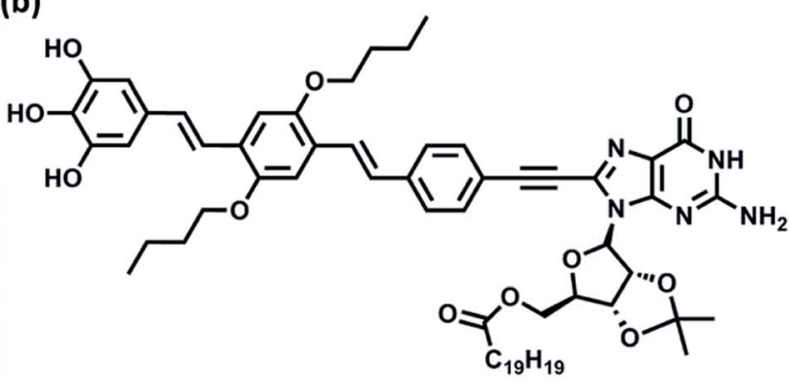

Fig. 14 (a) High resolution STM images of OPV-G2 on HOPG surface. Inset: tentative models of various structural features in STM images; (b) structure of OPV-G2. (Reproduced with permission from ref. 94 @ 2010, American Chemical Society).
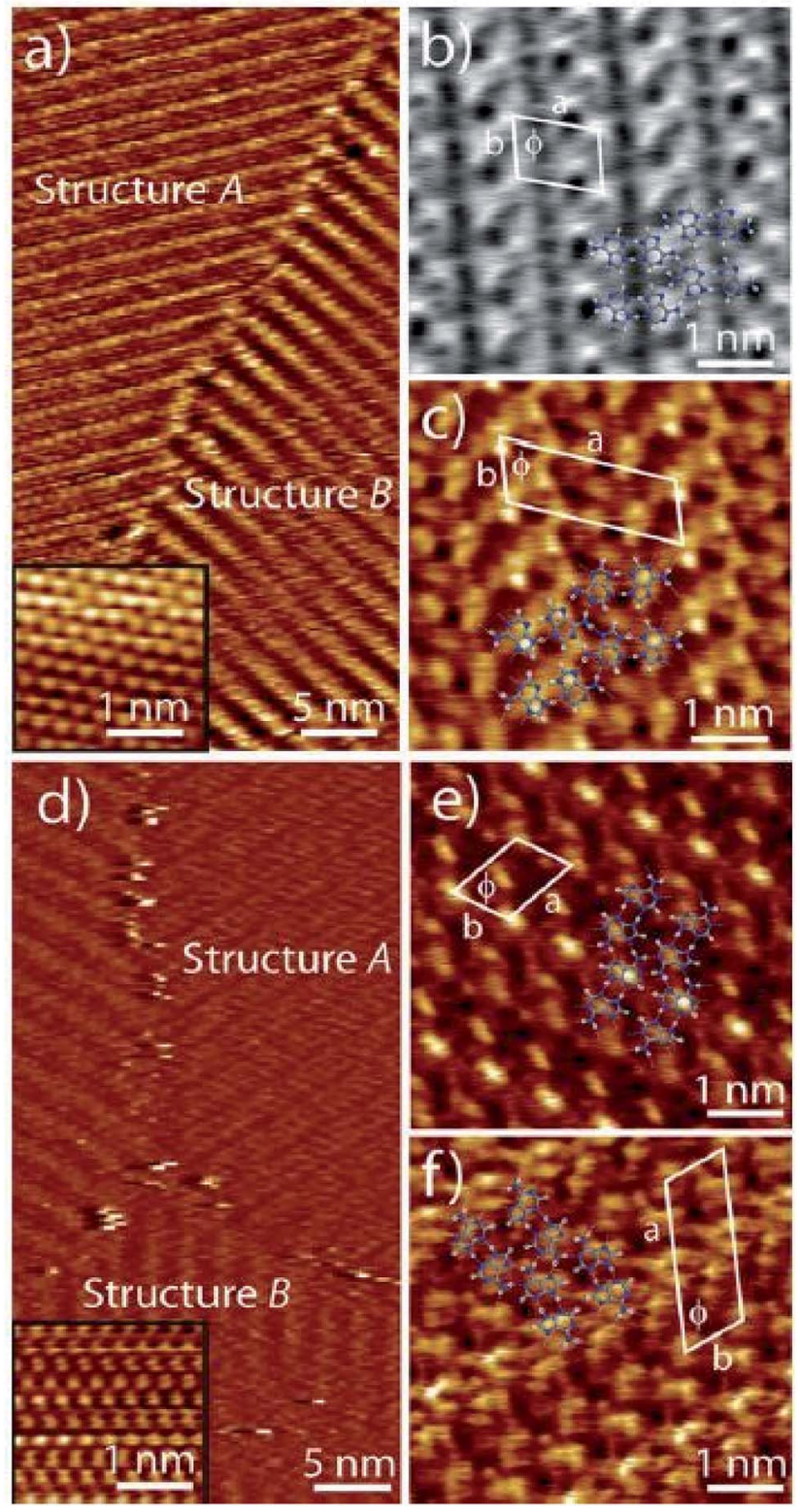

Fig. 15 Co-adsorption of adenine with L-serine $(\mathrm{a}-\mathrm{c})$ and with L-tyrosine $(d-f)$ revealing pure adenine domains by STM imaging. (Reproduced from ref. 95 with permission from The Royal Society of Chemistry).
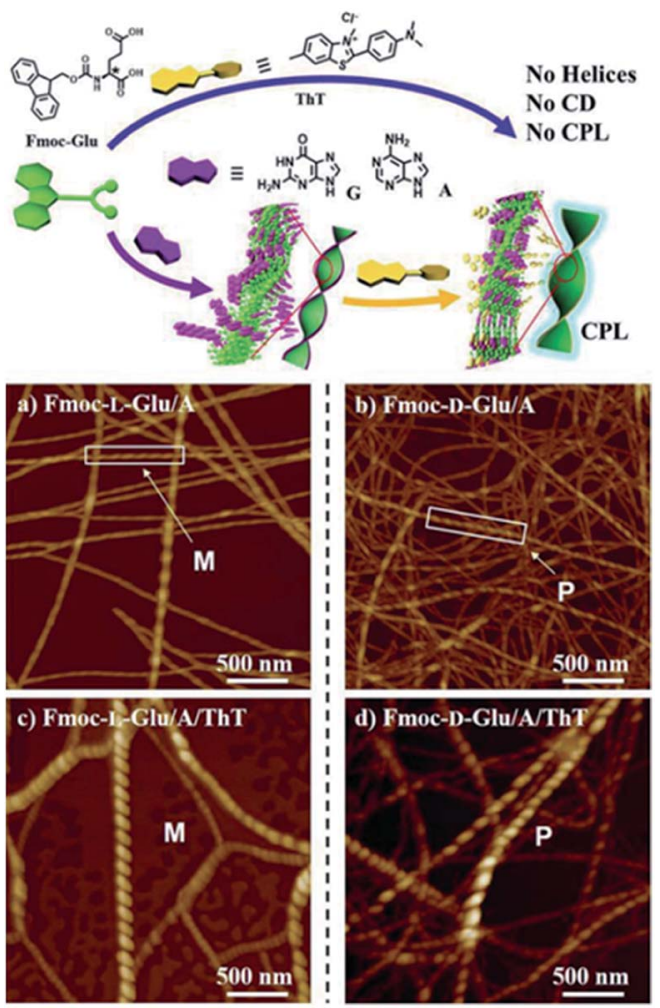

Fig. 16 Helical supramolecular fibres depicted by AFM images of (a) Fmoc-L-Glu/adenine; (b) Fmoc-D-Glu/adenine; (c) Fmoc-L-Glu/ adenine/ThT (d) Fmoc-D-Glu/adenine/ThT. (Reproduced from ref. 22 with permission from (c) 2016 Wiley-VCH Verlag GmbH \& Co. KGaA, Weinheim)

the resulting adenine functionalized copolymer afforded formation of highly-ordered nanostructures due to facile stacking interactions in adenine. ${ }^{90}$ Notably, thymine did not exhibit special surface features. In a related study, synthesis of adenine/thymine functionalized acrylic ABA triblock copolymers was carried out via modified chain transfer polymerization method. This triblock copolymer self-organized to afford microphase-separated structures, supported by stacking and hydrogen bonding interactions, as observed by AFM studies. ${ }^{91}$

Another report by Long and coworkers described synthesis of cytosine and ureido-cytosine functionalized diacrylic 


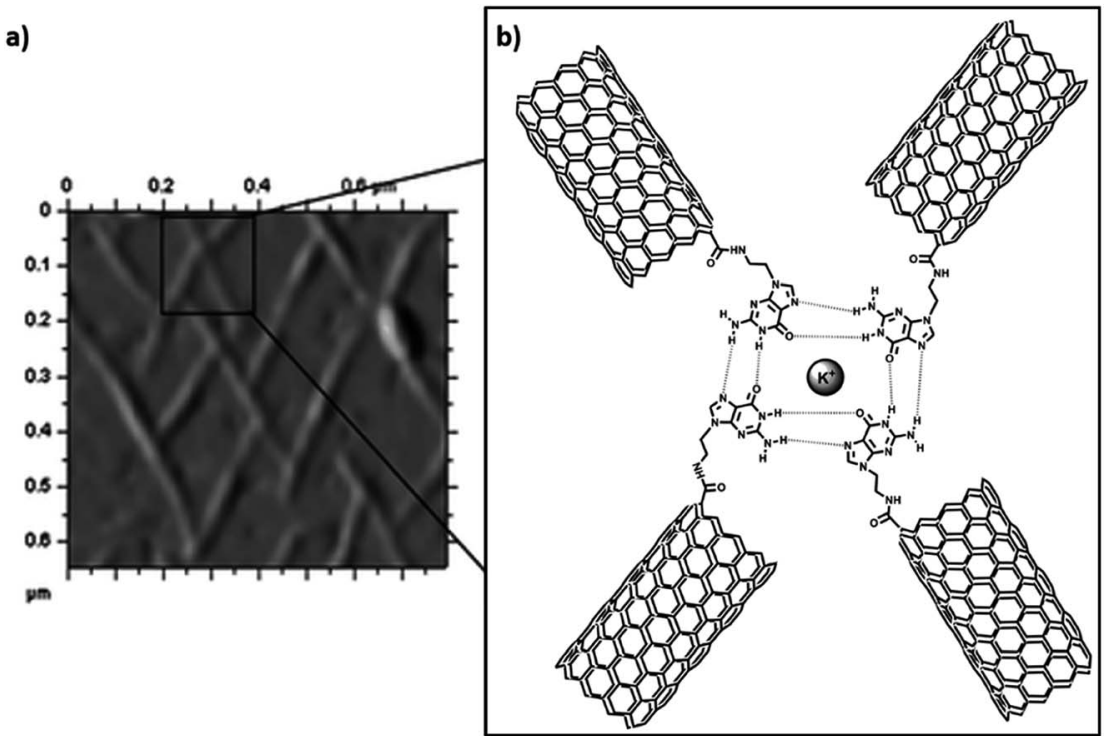

Fig. 17 (a) AFM image of Guanine-SWCNT 1 with potassium ions on mica surface; (b) proposed model CNT alignment. (Reproduced with permission from ref. 108 The Royal Society of Chemistry).

copolymers, where cytosine-modified copolymer revealed irregular shapes, while ureido-cytosine analog formed nanofibrillar structures. This self-organization behavior accounted for improved thermal and mechanical properties making them promising candidates for adhesives and thermoplastic elastomers (Fig. 13). ${ }^{\mathbf{9}}$

Novel biocompatible nucleobase-grafted polycaprolactones consisting of adenine and uracil were prepared and their morphologies were analyzed using AFM and TEM. Both copolymers were studied separately and as a blend, to ascertain favorable adenine-uracil interactions. Nucleobase functionalization enabled transformation of star-like morphology of caprolactone to nanospherical shape of the blend, perhaps due to cooperative hydrogen bonding interactions. ${ }^{93}$

Investigation concerning self-assembly of guanine-/ guanosine-capped oligo( $p$-phenylene-vinylene) oligomers revealed that oligomer formation and ensuing nanoassemblies were organized primarily through the formation of G-quartets, mediated by monovalent cations. These nanoassemblies were found refractory towards concentration and temperature modifications and stable towards disaggregation (Fig. 14). ${ }^{\mathbf{9 4}}$

\section{Co-adsorption of nucleobase and peptides}

Amino acid sidechains in peptide also have the ability to interact with nucleobases through the Hoogsteen face. Stability of two dimensional structures obtained by co-adsorption of adenine with L-serine (L-Ser) and L-tyrosine (L-Tyr), revealed that adenine-adenine networks are energetically stronger compared to Ser- and Tyr-adenine interactions. This was ascertained by co- a)

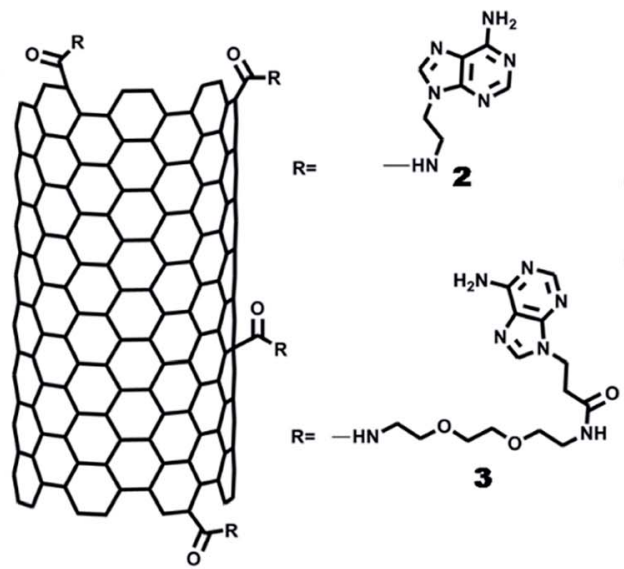

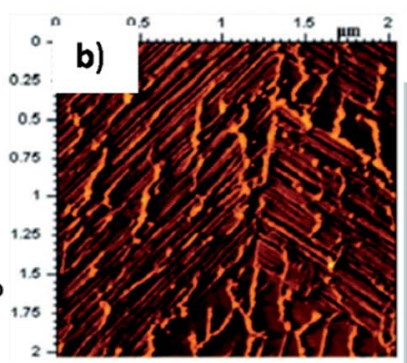

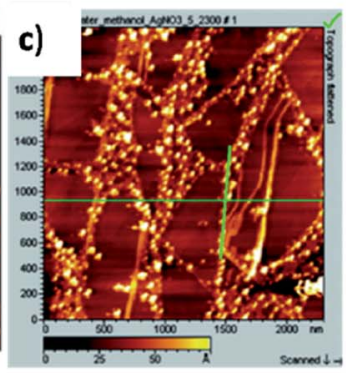

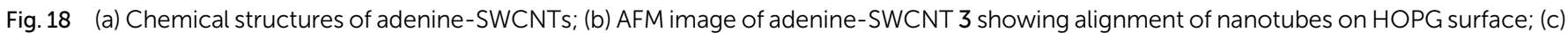
AFM image of $\mathrm{Ag}(\mathrm{I})$ complex of adenine-SWCNT 2. (Reproduced with permission from ref. 109 (C) 2009 American Chemical Society). 


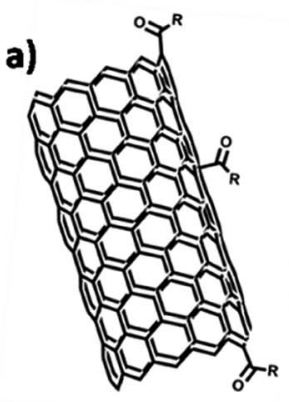

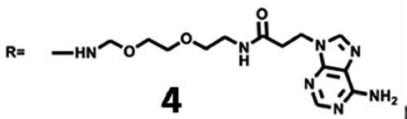

$\mathbf{R}=$

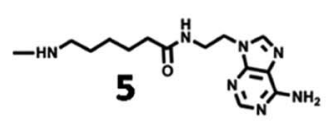

$\mathbf{R}=$

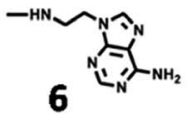
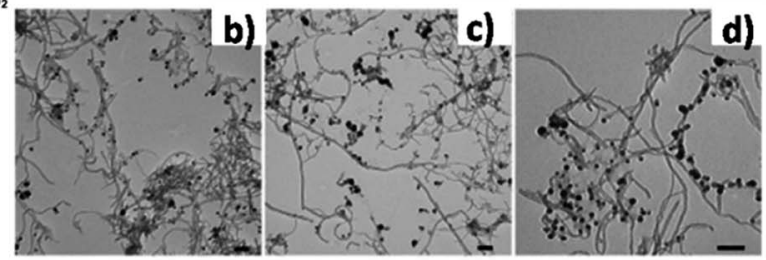

e)<smiles>CC1=CC(=O)C=CC(=O)C1=O</smiles>

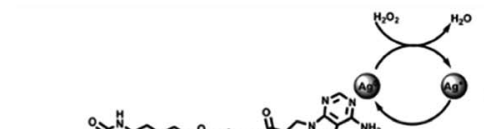

Fig. 19 (a) Chemical structures of adenine-MWCNTs 4-6. TEM micrographs of adenine-MWCNT hybrids (b) 4 (c) 5 and (d) 6 complexed with silver ions. Scale bars $=100 \mathrm{~nm}$; (e) silver complexed adenine-MWCNT 4 hybrid in catalytic conversion. (Reproduced with permission from ref. 110 @ 2011 WILEY-VCH Verlag GmbH \& Co. KGaA, Weinheim).

deposition of adenine with amino acids, which resulted in morphologies that could be ascribed to homoadenine networks suggesting preponderance of self-sorting was in favor of homoadenine system (Fig. 15). ${ }^{95}$

Sleiman and coworkers reported nucleobase-peptide amphiphiles based on dityrosine peptide and evaluated their solution-phase self-organization by microscopy methods. Growth of morphologies ranging from rod-like or helical micelles to the formation of nanoribbons was observed. ${ }^{96}$ The potential of peptide assembly and amphiphilic character led to large-scale scaffolds embellished with addressable nucleobases for recognition.

Liu and coworkers demonstrated chirality induction to achiral Thioflavin $\mathrm{T}$ (ThT) dye from self-assembled, fiber-like helical structures arising from the interaction of Fmocglutamic acid and achiral guanine or adenine nucleobases. a)

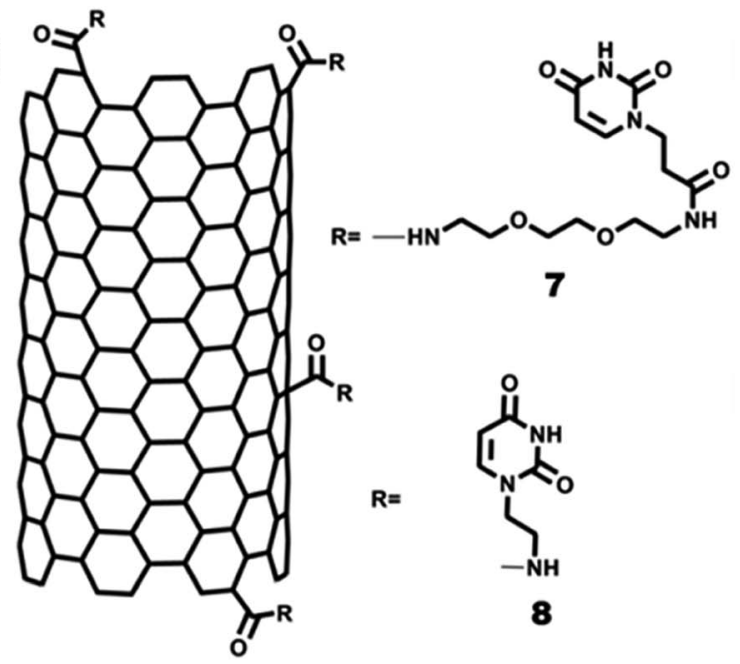

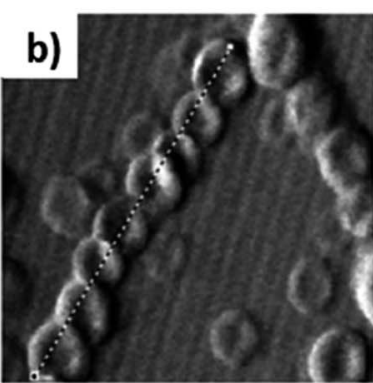

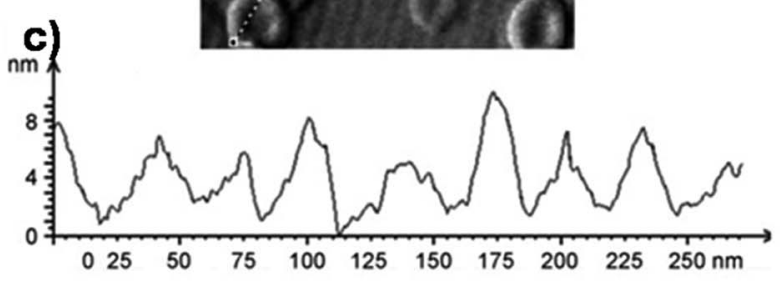

Fig. 20 (a) Chemical structures of uracil-SWCNTs 7 and uracil-SWCNT 8; (b) AFM image of uracil-SWCNT 7 on HOPG showing nanorings forming helix-type structure; (c) height-diameter profile of nanorings. (Reproduced with permission from ref. 111 @ 2011 WILEY-VCH Verlag GmbH \& Co. KGaA, Weinheim). 
a)

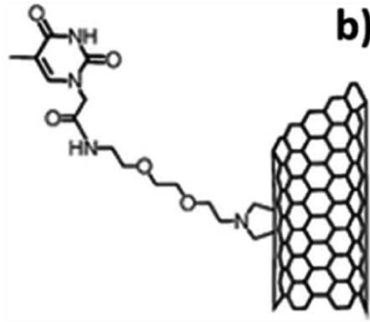

Thymine-SWCNT 9

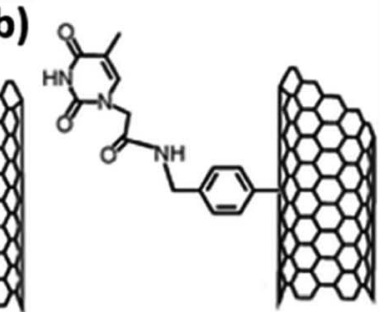

Thymine-st-MWCNT 10 Thymine-MWCNT 11

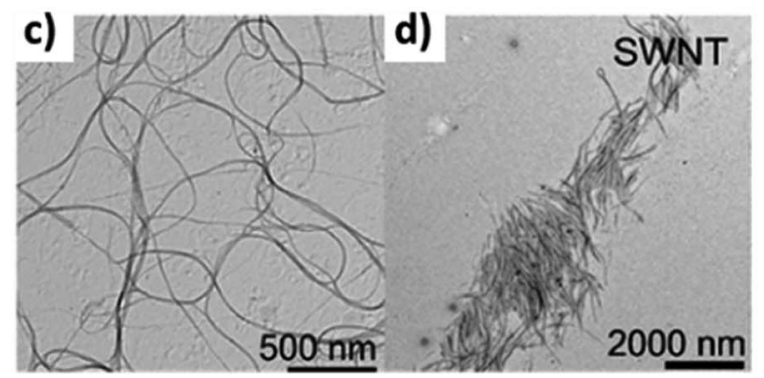

Fig. 21 Chemical structures of thymine-functionalised CNTs formed by: (a) 1,3-dipolar cycloaddition (b) arylation reaction. TEM images (c) 9 in DMF (d) 9 in DCM. (Reproduced with permission from ref. 114 The Royal Society of Chemistry).

Interestingly, ThT fluorescence changed from transparent to yellow and cyan, when added to gel fibers. This property was further confirmed by circular polarised fluorescence studies (Fig. 16). ${ }^{22}$

\section{Surface modification by nucleobase- CNT hybrids}

Carbon nanotubes (CNTs) are sparingly soluble in most solvents, which restricts their widespread use in certain applications. Covalent functionalization strategies are commonly used to improve upon physicochemical characteristics of CNTs, which includes functionalization at end tips and CNT sidewalls. ${ }^{97,98}$ Consequently, suitably altered functionalised CNTs are attractive candidates for biomedical applications as well as material development approaches.99-102 There are numerous examples CNTs functionalised with small organic molecules,${ }^{103}$ polymers,${ }^{104}$ peptides,${ }^{105}$ peptide nucleic acids,${ }^{106}$ nucleic acids ${ }^{107}$ and nucleobases. ${ }^{108-115}$
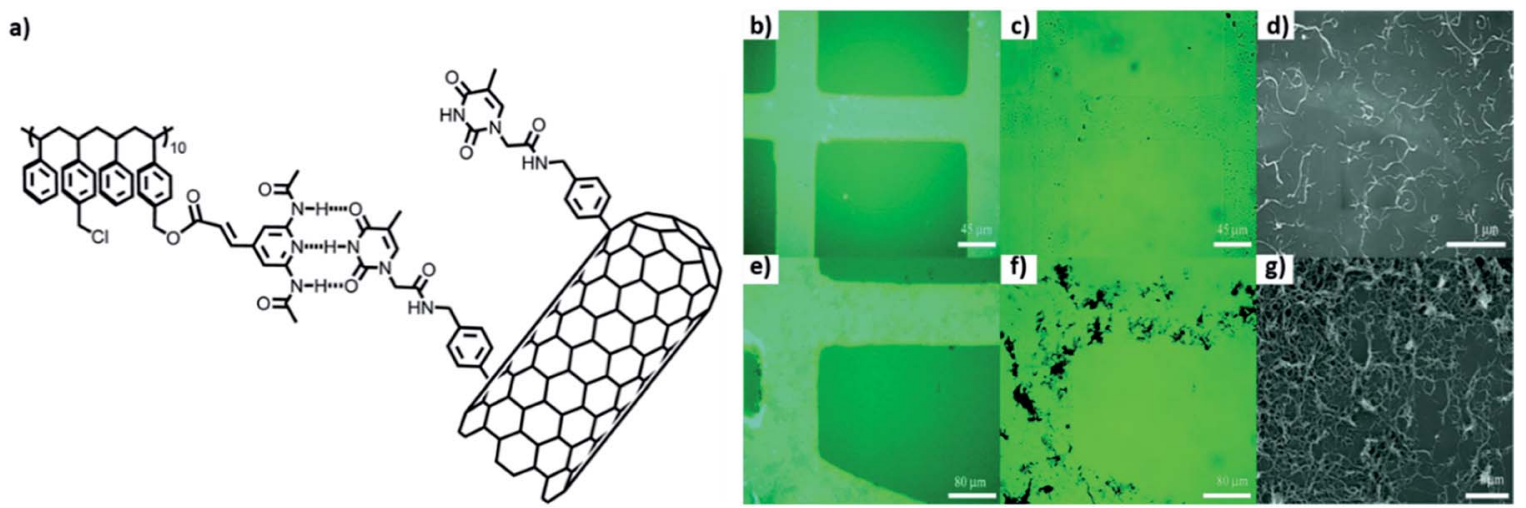

Fig. 22 (a) Chemical structure of PS1, thymine-MWCNTs; images of patterned surface by (b and e) fluorescence, (c and f) optical and (d and g) scanning electron microscopy, after deposition of a dispersion of Thymine-MWCNTs in DMF (b-d) and $\mathrm{CHCl}_{3}$ (e-g).(Reproduced with permission from ref. 115 @ 2012 American Chemical Society).
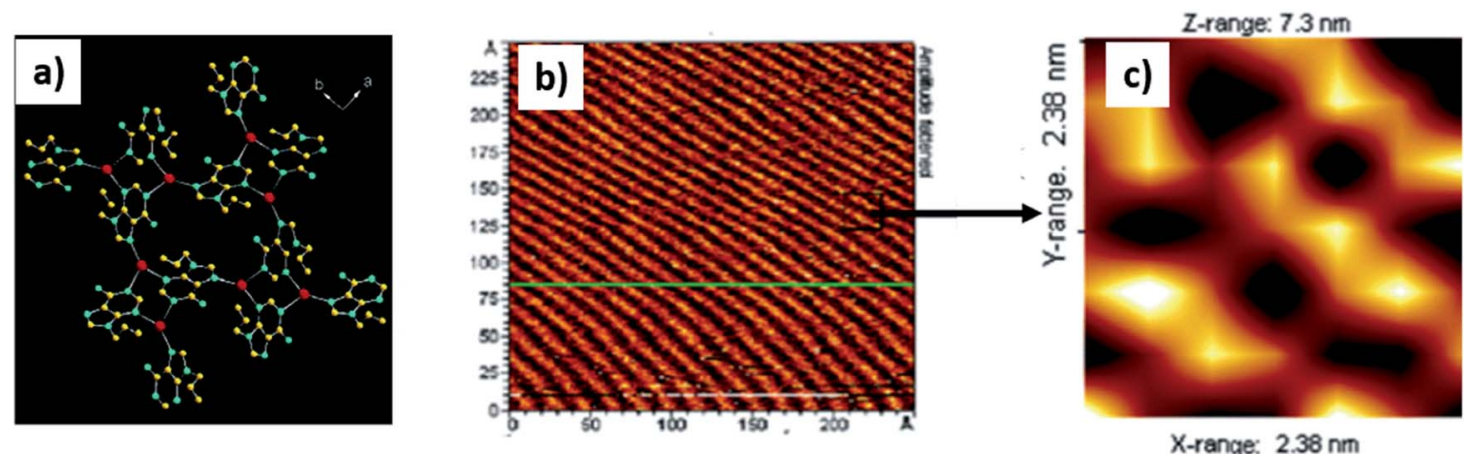

Fig. 23 (a) Adenine metallamacrocycle 1. (b) AFM image of complex 1 on HOPG surface; (c) magnified image of (b) showing zig-zag assembly. (Reproduced with permission from ref. 117 @ 2006 American Chemical Society). 

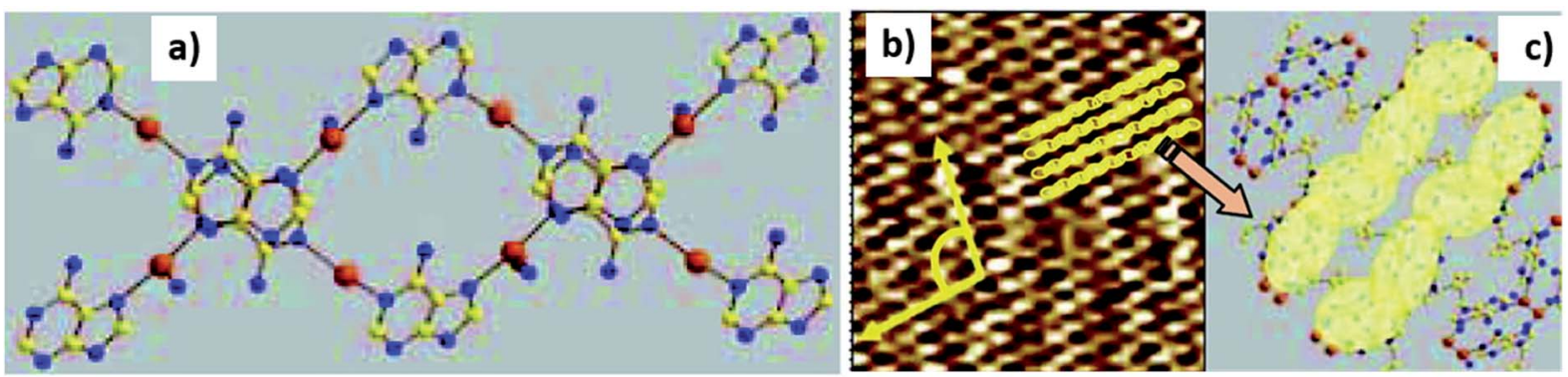

Fig. 24 (a) Double-stranded coordination helicate 2. (b) AFM image of 2 on HOPG surface. Image size is $400 \times 400 \AA^{2}$; (c) proposed model of adenine-silver helicate deposition. (Reproduced with permission from ref. 118 @ 2007 American Chemical Society).

Inherent hydrogen bond-mediated assembly of nucleobases provided the impetus to explore self-assembly of guanine-single walled CNT hybrids on HOPG surface. Covalently functionalised guanine-SWCNT (SWNT: single walled carbon nanotubes) 1 appeared as small bundles on TEM analysis, which in the presence of $\mathrm{K}^{+}$ions $(4: 1)$, indirectly revealed a G-quartet type of self-assembled pattern on HOPG/mica surface (Fig. 17a), thereby aligning CNTs on surface. ${ }^{108}$

In another example, self-organisation of adenine-SWCNT -triethyleneglycol (TEG) linker and its interaction with silver ions was studied on HOPG with the help of AFM and TEM. Adenine-SWCNT 3 showed horizontally aligned nanotube on HOPG surface (Fig. 18b), which was ascribed to paralleloriented assembly. On the contrary, AFM images of adenineSWCNT 2, without TEG chain, revealed the occurrence of a fibrous morphology, primarily supported by van der Waals interactions. On interaction with silver ions, hybrid adenine-
SWCNT 2 resulted in deposition of silver nanoparticles over nanotube surface (Fig. 18c). ${ }^{109}$ It was surmised that such nucleobase-carbon nanotubes hybrids, along with metal coordination, could provide a new platform for biosensors and heterogeneous catalysis.

Silver coated adenine-CNT hybrids were employed as heterogeneous catalyst for the conversion of 2-methylhydroquinone to 2-methylbenzoquinone. Three multiwalled CNT (MWCNT) derivatives (4-6) were prepared (Fig. 19a), followed by their interaction with silver ions as judged by TEM analysis (Fig. 19b-d). Catalytic activity of $\mathbf{4} / \mathrm{Ag}$ hybrid was demonstrated by achieving oxidation of 2-methylhydroquinone to 2-methylbenzoquinone, with successful catalyst recycling without appreciable loss of catalytic activity (Fig. 19e). ${ }^{110}$

Self-organisation of covalently functionalized uracil-SWCNT 7 on freshly cleaved HOPG surface afforded formation of nanoring structures (cross-section: $\sim 50-70 \mathrm{~nm}$; height: $\sim 20-25$
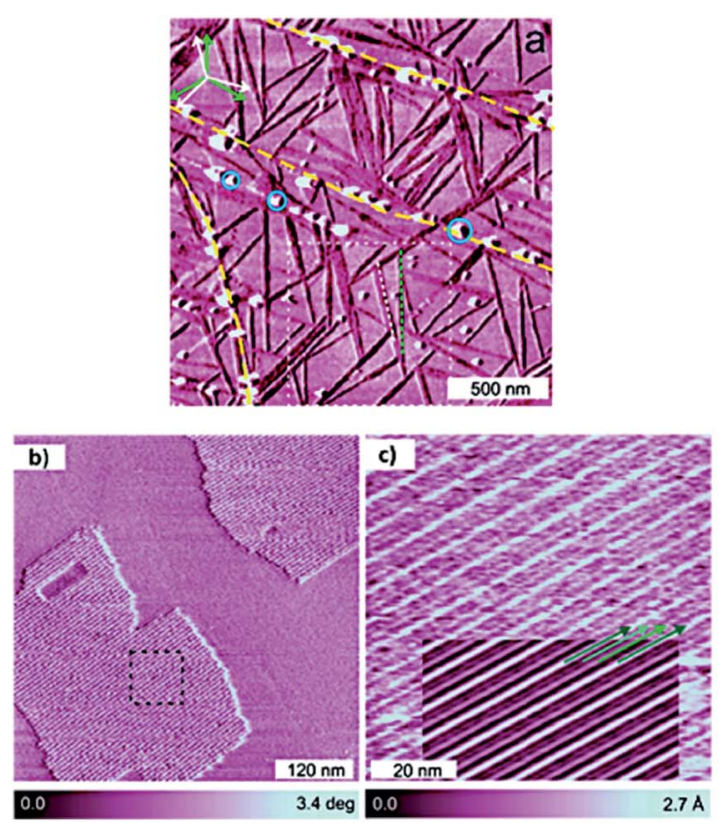

d)

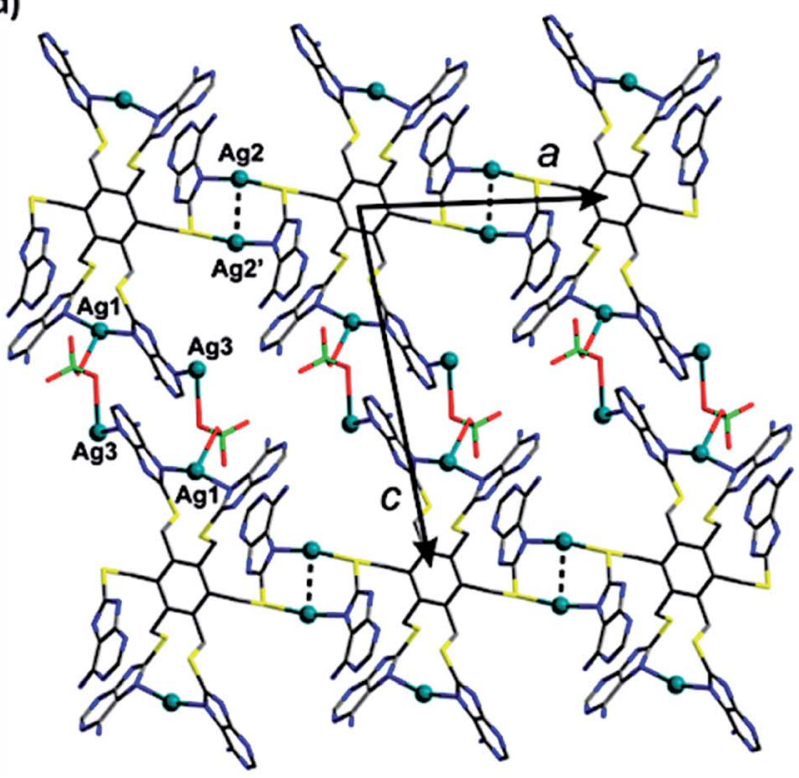

Fig. 25 (a) AFM phase image of ultrathin film of hexapodal silver complex 3 on HOPG surface. Graphite multiatomic terrace edges are shown in yellow dashed lines and with growth direction of rotational and mirror domains of 1D chains; (b) AFM constant height phase image of 2D domains; (c) high-resolution AFM topography image of black square region in (b); (d) plane containing Ag-coordinated polymer. (Reproduced with permission from ref. 120 @ 2017 American Chemical Society). 

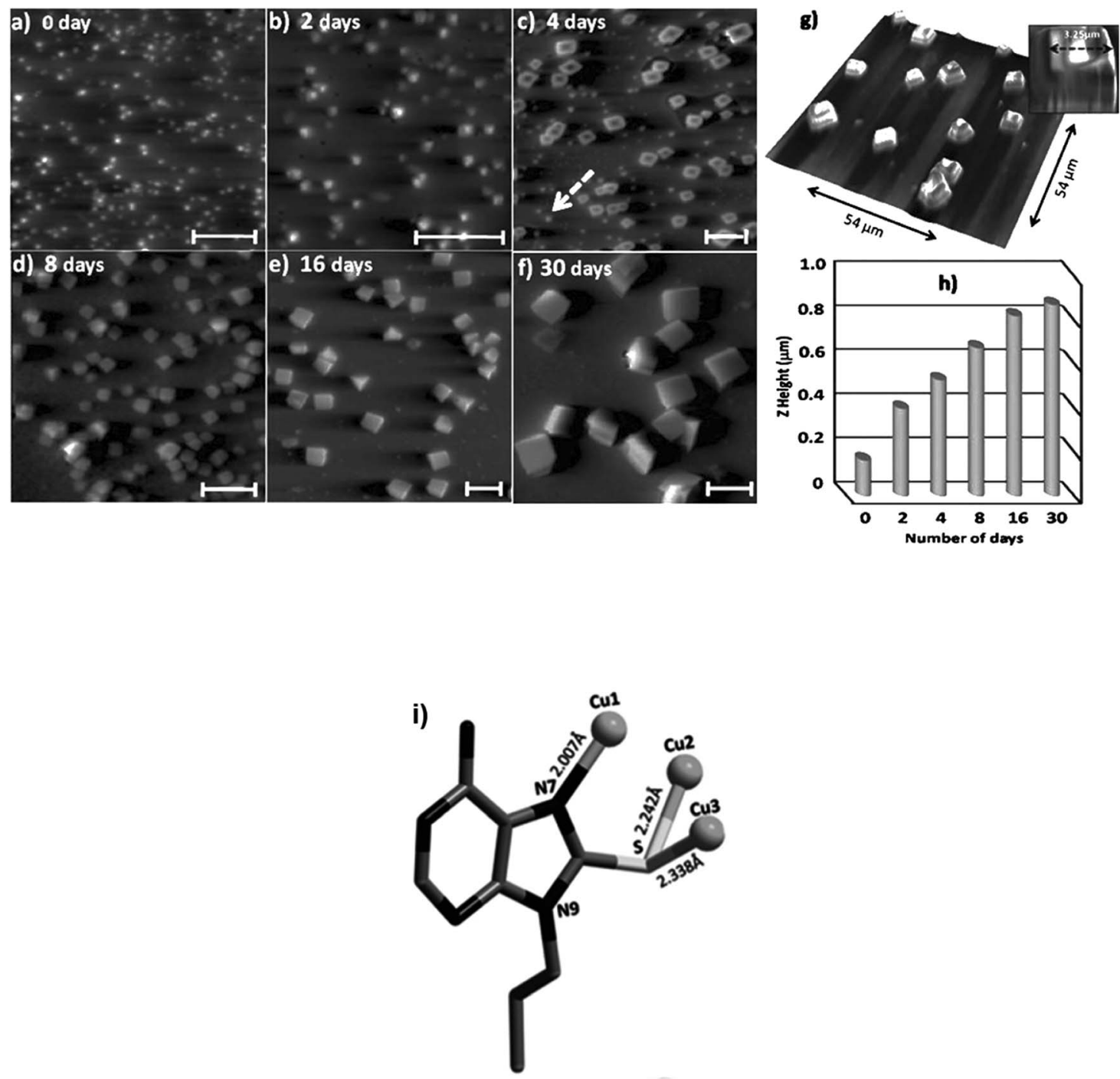

Fig. 26 (a-f) 2D AFM image of time-dependent solution phase growth of copper complex on glass surface. Scale bars: $5 \mu$ m; (g) 3D AFM image of cuboidal aggregate; (h) periodic increase in Z-height over 0 to 30 days; (i) Crystal structure of copper complex 4 (Reproduced with permission from ref. 124 @ 2014 WILEY-VCH Verlag GmbH \& Co. KGaA, Weinheim).

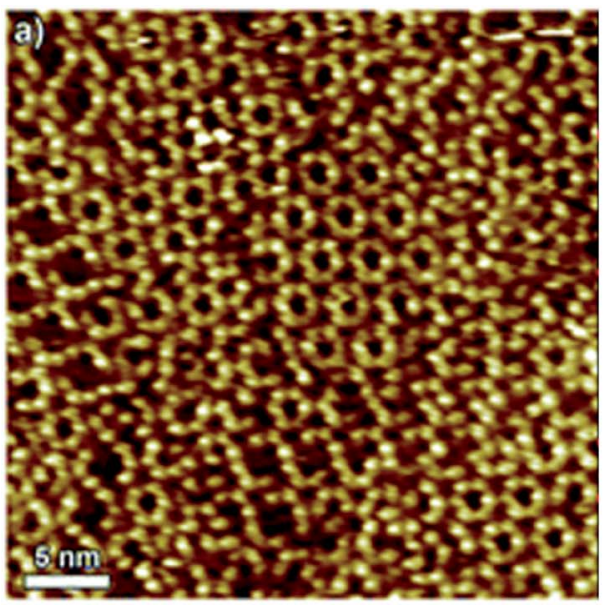<smiles></smiles>

Fig. 27 (a) STM image of Pt-complex 5 on HOPG; (b) structure of complex 5. (Reproduced from ref. 126 with permission from The Royal Society of Chemistry). 

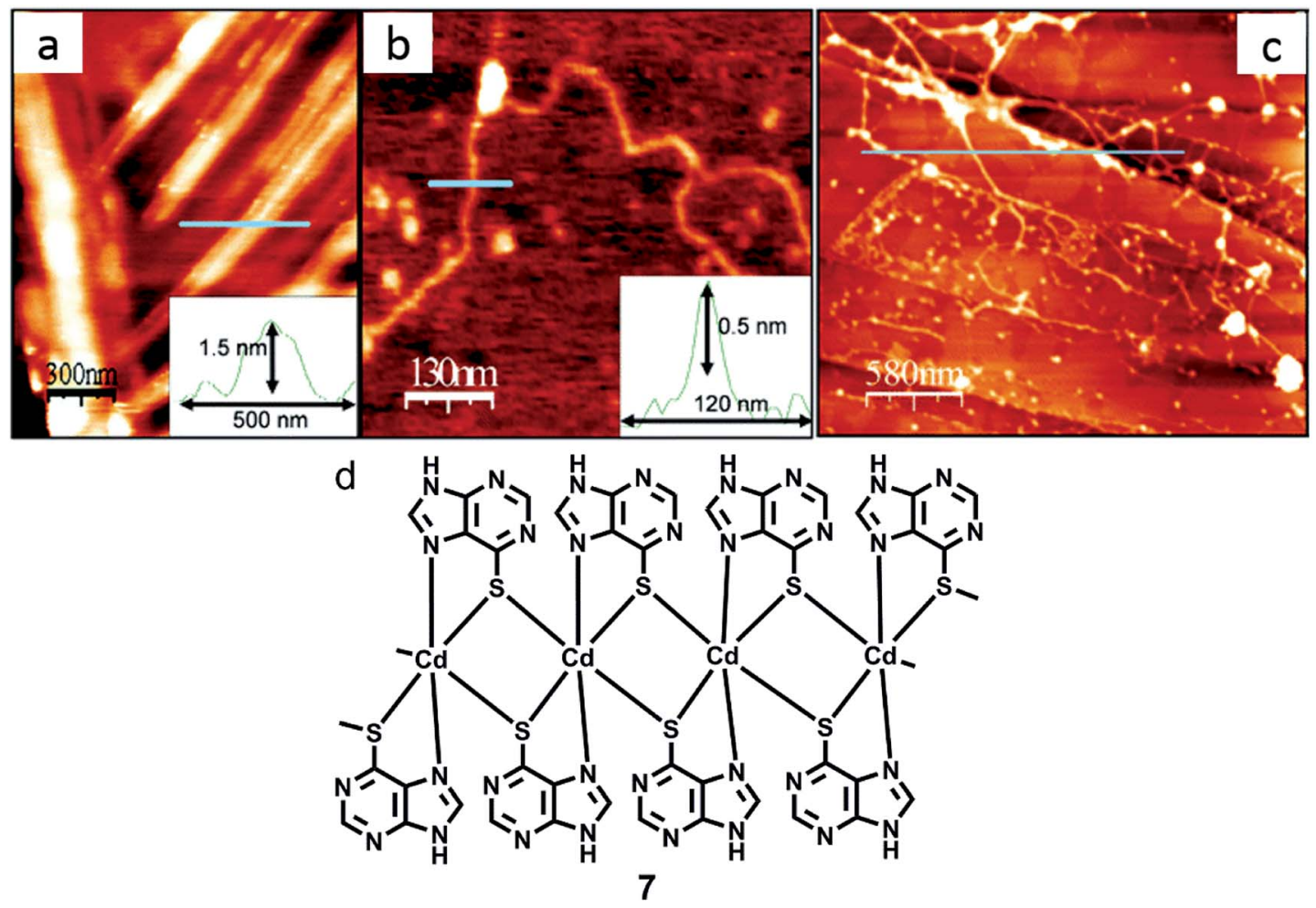

Fig. 28 (a) AFM image of crystals acquired by treating 7 with $\mathrm{NaOH}$; (b) AFM image of a single polyanion; (c) AFM micrograph of fibers acquired by in situ reaction on HOPG; (d) structure of 7. (Reproduced with permission from ref. 127 (c) 2006, American Chemical Society).

$\mathrm{nm}$ ), as observed by AFM analysis (Fig. 20b). Nanoring formation could be ascribed to surface adsorption of SWCNT, followed by hydrogen bonding between uracil-uracil base pair. Notably, uracil-SWCNT 8, devoid of the TEG chain, afforded fibrils or tubes on HOPG surface. ${ }^{111}$

H-bond driven self-assembly of thymine-functionalized CNTs in organic solvents has also been investigated. TEM analysis revealed dispersion of thymine-CNTs in dimethyl formamide (DMF), a solvent that could interact with nucleobase moiety (Fig. 21c) and dichloromethane (DCM), a noncompetitive solvent, affording formation of diverse superstructures directed by thymine-thymine interaction (Fig. 21d). ${ }^{114}$

Selective deposition of thymine-functionalized MWCNTs was achieved on patterned polystyrene matrix using a combination of "top-down" as well as "bottom-up" approaches.
Modified MWCNTs were able to interact with the polystyrene matrix having 2,6-di(acetylamino)-4-pyridyl moieties, through complementary three-point hydrogen bonding, as studied by various microscopy techniques (Fig. 22b-g). ${ }^{115}$

\section{Surface modification by metal- nucleobase complexes}

Predisposed metal coordination sites present of nucleobases could be used to construct tailored metal-nucleobase frameworks for designed applications. ${ }^{116}$ For example, adenine interacts efficiently with metal ions to create a vast number of coordination polymers in the solid state, with a distinct possibility of surface patterning, ${ }^{117-120}$ in addition to such custom surfaces being amenable to further processing. ${ }^{121-123}$
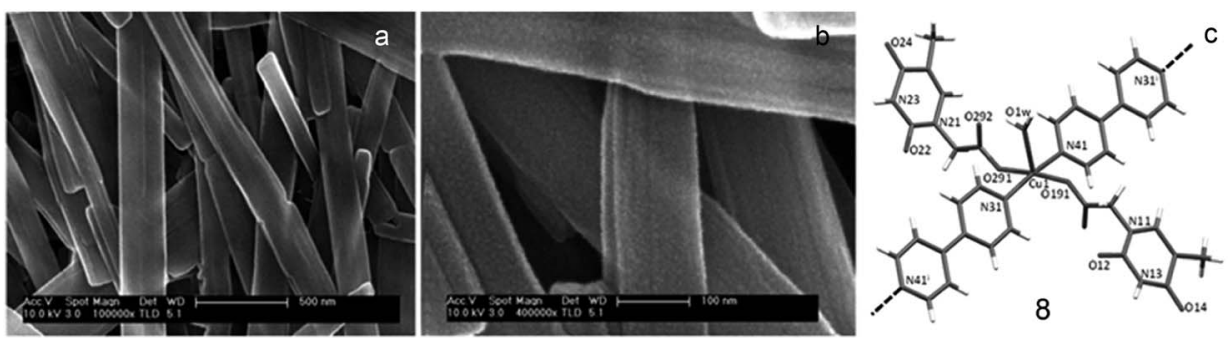

Fig. 29 (a) SEM image of nanoribbons of 8; (b) enlarged view of (a); (c) structure of 8. (Reproduced from ref. 128 with permission from $@ 2017$ Wiley-VCH Verlag GmbH \& Co. KGaA, Weinheim). 
Table 1 Table depicting surface morphologies of selected compounds

S. no. Compound Substrate Topography

\section{Adenine (A) and its analogs}

1 9-Icosyladenine

2 Adenine-C22

3 Adenine

4 Adenine

5 Adenine

\section{Thymine (T)}

6 Thymine

7 Thymine

8 Thymine

9 Thymine

\section{Guanine (G) and its analogs}

10 Guanine

$11 \quad \mathrm{C}_{6}-\mathrm{C}_{10}$ alkyl guanines

$12 \mathrm{C}_{12}$ or higher alkyl guanines

13 Guanine

14 Guanine

15 Guanine

\section{Cytosine (C)}

16 Cytosine

\section{Co-adsorption of different nucleobases}

$\begin{array}{ll}17 & \mathrm{~A}+\mathrm{T} \\ 18 & \mathrm{G}+\mathrm{C} \\ 19 & \mathrm{G}+\mathrm{U} \\ 20 & N \text {-aryl modified cytosine and guanine } \\ 21 & \mathrm{C}+\mathrm{G} \\ 22 & \mathrm{C}+\mathrm{A}\end{array}$

\section{Nucleobase functionalised molecules}

23 A-A dimer functionalized by oligo(phenyleneethynylene)

24 T-T dimer functionalized by oligo(phenyleneethynylene)

25 Mixture of functionalized A-A and T-T dimers

26 9-Propyladenine and tetra-TP

\section{Nucleobase functionalised polymers}

27 OPV-G2

\section{Nucleobase and peptides}

28 adenine + L-Ser

29 adenine + L-Tyr

30 Fmoc-L-Glu/adenine

31 Fmoc-D-Glu/adenine

32 Fmoc-L-Glu/adenine/ThT

33 Fmoc-D-Glu/adenine/ThT

\section{Nucleobase-CNT hybrids \\ 34 Guanine-SWCNT1 \\ 35 Adenine-SWCNT 3 \\ 36 Silver(I) complexed with adenine-MWCNTs 4, 5 and 6 \\ 37 Uracil-SWCNT7 \\ 38 Thymine-SWCNT 9 \\ 39 PS1,Thymine-MWCNT}

HOPG Two different phases: $\alpha$ - and $\beta$-phase 62

HOPG Two different phases: $\alpha$ - and $\beta$-phase 63

HOPG 2D networks of adenine dimers $\quad 65$

$\mathrm{Au}(111) \quad$ Two different types of islands with four and two molecules per unit cell $\quad 69$

$\mathrm{Cu}(110)$ 1D dimeric chains

HOPG Zig-zag chain like structure

65

$\mathrm{Au}(111) \quad$ Randomly oriented 1D filaments (low coverage) and 2D island-like growth $\quad 72$ patterns (high coverage)

$\mathrm{Cu}(111) \quad 2 \mathrm{D}$ island formation

$\mathrm{Cu}(110)$ Parallel aligned 1D chains consisting of oval-shaped structures

HOPG Monolayers

HOPG Linear ribbon-like structures

$\mathrm{Au}(111) \quad 2 \mathrm{D}$ islands with G-quartet like arrangement 78

$\mathrm{Cu}(111) \quad$ Close-packed 2D square lattices $\quad 73$

$\mathrm{Au}(111) \quad$ Self-assembled guanine islands $\quad 78$

$\mathrm{Au}(111) \quad$ Zigzag filaments and five- and six-membered rings $\quad 81$

HOPG Well-ordered 2D supramolecular nanoassemblies 65

HOPG Ordered nanoassemblies with three distinct domains 83

HOPG 2D cyclic supramolecular nanostructure $\quad 84$

$\mathrm{Au}(111) \quad$ Porous supramolecular assembly 84

$\mathrm{Au}(111) \quad$ Dense ring-like structures $\quad 86$

$\mathrm{Au}(111) \quad$ Large islands and zigzag chains $\quad 86$

HOPG Ordered rectangular pattern $\quad 87$

$\begin{array}{lll}\text { HOPG Sparse nanostructural pattern } & 87\end{array}$

HOPG Ordered rectangular pattern $\quad 87$

HOPG Self-assembled network

HOPG Nanoassemblies

HOPG Homoadenine networks

HOPG Homoadenine networks $\quad 95$

Mica Fibre-like helical supramolecular structures 22

Mica Fibre-like helical supramolecular structures 22

Mica Fmoc-adenine served as a matrix to transfer chirality to ThT 22

Mica Fmoc-adenine served as a matrix to transfer chirality to ThT 22

HOPG/ G-quartet type of self-assembled pattern 108

mica

$\begin{array}{ll}\text { HOPG Horizontal alignment of nanotubes } & 109\end{array}$

TEM Uniform distribution of silver, $\mathrm{Ag}(\mathrm{I})$ and $\mathrm{Ag}(\mathrm{II})$ ions over nanotubes 110

grid

HOPG Nanorings forming helix type structure $\quad 111$

$\begin{array}{ll}\text { TEM Formation of superstructure } & 113\end{array}$

grid

Glass/Si Selective deposition of Thymine-MWCNTs on patterned polystyrene matrix 114 
Table 1 (Contd.)

S. no. Compound

Substrate Topography

Ref.

Metal-nucleobase complexes

40 Complex 1

41 Complex 2

42 Complex 3

MOF 4

Complex 5

Complex 7

46 Coordination polymer 8

HOPG Repetitive zig-zag assembly resembling crystal structure

HOPG Patterned deposition resembling crystal structure

117

HOPG Long and thin 1D needle like features

Glass

Homogeneously-sized nanocuboidal morphology after 30 days

123

HOPG Polygonal discrete cyclic motifs

125

HOPG Fibre-like structures

$\mathrm{SiO}_{2} \quad$ Uniform crystalline nanoribbons

In one example, 9-allyladenine afforded silver-mediated metallamacrocyclic quartet $\mathbf{1}$, where all the imino nitrogens of adenine coordinated to silver ions. Complex 1 was transferred on HOPG surface and it showed a well-ordered arrangement consisting of a repetitive zig-zag assembly (Fig. 23b), which resembled the crystallographic signature in the crystal lattice. ${ }^{117}$

Similarly, crystals of an adenine-silver helicate (2), obtained by the interaction of 9-allyladenine with ammoniacal silver nitrate, were deposited on HOPG surface. Non-contact mode AFM images revealed persistent silver-adenine interaction via pattered deposition that closely resembled crystal structure of 2 (Fig. 24a-b). ${ }^{118}$ Such patterning was not formed when 2 was deposited on $\mathrm{Si}(100)$ wafer or mica, suggesting the importance of favourable surface properties in stabilizing patterns.

A $C_{3}$ symmetric hexaadenine ligand interacted with $\mathrm{AgClO}_{4}$ to form silver complex 3 , which showed energetically stable and high abundant 1D needle-like features over HOPG surface (Fig. 25a). A strong interaction between ligand and metal ions was evident from the chain growth over surface kinks and monoatomic steps. Notably, 2D growth was observed with increase in the thickness of monolayer (Fig. 25b and c), where formation of the proposed adlayer was assisted by bridging counterions (Fig. 25d). ${ }^{120}$

Additional metal coordinating sites in adenine was orchestrated by introducing a thiol substitution at the C8 position. Consequently, 8-mercapto-N9-propyladenine afforded a highly porous copper adenine framework upon interaction with cuprous iodide. Notably, time-dependent solution phase growth studies revealed conversion of seed-like particles of complex 4 at $0 \mathrm{~h}$ to a cuboidal morphology after $48 \mathrm{~h}$, finally culminating into homogeneous cuboidal morphology after 30 days (Fig. 26a-f). ${ }^{124}$

The effect of substitution at N9 position was investigated in $1, N^{6}$-ethenoadenine derivatives where N9 icosyl substitution afforded a well-ordered, uniform lamellar structure on HOPG surface, with alternate bright and dark stripes, where the dark ones represented alkyl chains and the bright ones the aromatic moieties. Notably, $\operatorname{Ag}(\mathrm{I})$ complexation with this ligand demonstrated a similar lamellar pattern, albeit with a slight difference in observed patterns. ${ }^{\mathbf{1 2 5}}$

Samori and coworkers synthesized a platinum-isocytosine complex $\mathbf{5}$, followed by its surface study on 1-phenyloctane/ HOPG interface. Interestingly, polygonal discrete cyclic motifs were observed, which were stabilized by hydrogen bonding between the isocytosine groups. Notably, formation of trimers, tetramers, pentamers, hexamers and half-hexamers were also surmised as explained by theoretical calculations (Fig. 27). ${ }^{\mathbf{1 2 6}}$

Zamora and coworkers synthesized 6-mercaptopurine and complexed it with $\mathrm{Cd}(\mathrm{II})$ salt to obtain a discrete cadmium complex 6 or a polymeric structure 7 , along with the formation of several interconvertible intermediates. AFM was used to study these reactions on HOPG surface, including an in situ deprotonation event, which was analyzed on the mica surface (Fig. 28). ${ }^{127}$

In another report, Amo-Ochoa and coworkers reported reaction of thymine-1-acetic acid, copper nitrate and 4, $4^{\prime}$ bipyridine in aqueous medium, resulting in the formation of coordination polymer 8 as crystalline nanoribbons. The latter exhibited selectivity for single-stranded adenine-based oligonucleotides on the basis of adenine-thymine interactions. Remarkably, these nanoassemblies show low cytotoxicity and exhibited potential as oligonucleotide nanocarriers for cellular delivery (Fig. 29). ${ }^{128}$

Although it is impossible to review the entire literature available in this area, we however present an overview to reiterate the potential of nucleobases and their conjugates in achieving desired metal ion interaction and their natural ability to interact with surfaces to afford facile patterning for advanced applications. The following table gives a snap-shot of model compounds, the preferred substrate for interaction studies and type of topography obtained subsequent to surface adsorption (Table 1).

\section{Conclusions}

Surface modifications achieved by heterocyclic natural nucleobases, nucleobase-functionalised carbon nanotubes (CNTs) and metal-nucleobase coordination polymers, are promising candidates for novel materials and for transferring interesting properties onto custom surfaces. ${ }^{44}$ Multicomponent discrete complexes, mixtures and nucleobase-terminated entities further enrich the repertoire and enhance the possibilities of using these systems, consisting of naturally evolved hydrogen bonding sites, for constructing hierarchically complex supramolecular networks and nanoarchitectures. Additionally, immobilization of nucleobases and their derivatives (including metal adducts) on (conducting) surfaces also presents interesting paradigm for fast expanding biochip technology efforts, 
necessary for rapid identification and unequivocal detection of important analytes. It could be envisaged that several other areas of custom surface design and applied platforms for detection and device fabrication will also benefit from the continued progress with nucleobase assemblies and transfer of their properties to custom surfaces.

\section{Conflicts of interest}

There are no conflicts to declare.

\section{Acknowledgements}

We acknowledge CSIR for SPM fellowship (RKS), MHRD for predoctoral fellowship (IA) and Center for Nanoscience, IIT Kanpur, for support (RKP). SV thanks DST for J. C. Bose National Fellowship and the ongoing work in his laboratory is also supported by DST Nano Mission.

\section{References}

1 M. Moradi, L. G. Tulli, J. Nowakowski, M. Baljozovic, T. A. Jung and P. Shahgaldian, Angew. Chem., Int. Ed., 2017, 56, 14395-14399.

2 J. Lee, A. J. Kalin, T. Yuan, M. Al-Hashimi and L. Fang, Chem. Sci., 2017, 8, 2503-2521.

3 T. Nijs, F. J. Malzner, S. Fatayer, A. Wäckerlin, S. Nowakowska, E. C. Constable, C. E. Housecroft and T. A. Jung, Chem. Commun., 2015, 51, 12297-12300.

4 J. R. Eskelsen, K. J. Phillips, K. W. Hipps and U. Mazur, Chem. Commun., 2015, 51, 10-13.

5 X.-Y. Zhu, B. Tu, G.-J. Hu, Q.-J. Fang, J.-J. Qi, X.-W. Xiao, Y.-F. Geng and Q.-D. Zeng, Phys. Chem. Chem. Phys., 2018, 20, 6383-6389.

6 Y. Yu, J. Lin and S. Lei, RSC Adv., 2017, 7, 11496-11502.

7 A. Eberle, A. Nosek, J. Büttner, T. Markert and F. Trixler, CrystEngComm, 2017, 19, 1417-1426.

8 R. Raval, Faraday Discuss., 2017, 204, 9-33.

9 A. Della Pia, D. Luo, R. Blackwell, G. Costantini and N. Martsinovich, Faraday Discuss., 2017, 204, 191-213.

10 H. Yang, L. Huang, K. Sun, K. Niu, Z. Cui, H. Zhang, Z. Wang, D. Yan and L. Chi, J. Phys. Chem. C, 2017, 121, 25043-25051.

11 Z. Li, H. Van Gorp, P. Walke, T. H. Phan, Y. Fujita, J. Greenwood, O. Ivasenko, K. Tahara, Y. Tobe, H. Uji-i, S. F. L. Mertens and S. De Feyter, Nanoscale, 2017, 9, 5188-5193.

12 H. Cao, A. Minoia, I. De Cat, J. Seibel, D. Waghray, Z. Li, D. Cornil, K. S. Mali, R. Lazzaroni, W. Dehaen and S. De Feyter, Nanoscale, 2017, 9, 18075-18080.

13 L. Zhang, J. Li, S. Qiu, X. Huang and Z. Zeng, New J. Chem., 2017, 41, 3260-3264.

14 C. Guo, J. D. Xue, L. X. Cheng, R. C. Liu, S. Z. Kang, Q. D. Zeng and M. Li, Phys. Chem. Chem. Phys., 2017, 19, 16213-16218.

15 Y. Hu, K. Miao, L. Xu, B. Zha, M. Long, X. Miao and W. Deng, Phys. Chem. Chem. Phys., 2017, 19, 19205-19216.
16 M. Dong, K. Miao, Y. Hu, J. Wu, J. Li, P. Pang, X. Miao and W. Deng, Phys. Chem. Chem. Phys., 2017, 19, 31113-31120.

17 J. Dash, A. J. Patil, R. N. Das, F. L. Dowdall and S. Mann, Soft Matter, 2011, 7, 8120.

18 X. Li, G. Wang, X. Ding, Y. Chen, Y. Gou and Y. Lu, Phys. Chem. Chem. Phys., 2013, 15, 12800.

19 J. T. Davis and G. P. Spada, Chem. Soc. Rev., 2007, 36, 296313.

20 M. El Garah, R. C. Perone, A. S. Bonilla, S. Haar, M. Campitiello, R. Gutierrez, G. Cuniberti, S. Masiero, A. Ciesielski and P. Samori, Chem. Commun., 2015, 51, 11677-11680.

21 C. Xing, H. Yuan, S. Xu, H. An, R. Niu and Y. Zhan, ACS Appl. Mater. Interfaces, 2014, 6, 9601-9607.

22 M. Deng, L. Zhang, Y. Jiang and M. Liu, Angew. Chem., Int. Ed., 2016, 55, 15062-15066.

23 H. Ozawa, N. Katori, T. Kita, S. Oka and M. A. Haga, Langmuir, 2017, 33, 11901-11910.

24 S. Zhang, Y. Geng, Y. Fan, W. Duan, K. Deng, D. Zhao and Q. Zeng, Phys. Chem. Chem. Phys., 2017, 19, 31284-31289.

25 G. Nandi, B. Chilukuri, K. W. Hipps and U. Mazur, Phys. Chem. Chem. Phys., 2016, 18, 20819-20820.

26 M. Kohmoto, H. Ozawa, L. Yang, T. Hagio, M. Matsunaga and M. A. Haga, Langmuir, 2016, 32, 4141-4152.

27 M. E. Garah, A. S. Bonilla, A. Ciesielski, A. Gualandi, L. Mengozzi, A. Fiorani, M. Iurlo, M. Marcaccio, R. Gutierrez, S. Rapino, M. Calvaresi, F. Zerbetto, G. Cuniberti, P. G. Cozzi, F. Paolucci and P. Samori, Nanoscale, 2016, 8, 13678-13686.

28 E. Moreno Pineda, T. Komeda, K. Katoh, M. Yamashita and M. Ruben, Dalton Trans., 2016, 45, 18417-18433.

29 J. Teyssandier, S. De Feyter and K. S. Mali, Chem. Commun., 2016, 52, 11465-11487.

30 S. B. Kim, R. D. Pike, J. S. D'Acchioli, B. J. Walder, G. B. Carpenter and D. A. Sweigart, Angew. Chem., Int. Ed., 2009, 48, 1762-1765.

31 F. Zamora, M. Pilar Amo-Ochoa, P. J. Sanz Miguel and O. Castillo, Inorg. Chim. Acta, 2009, 362, 691-706.

32 Z. Xiang, D. Cao and L. Dai, Polym. Chem., 2015, 6, 18961911.

33 Z. Li and H. C. Zeng, J. Am. Chem. Soc., 2014, 136, 56315639.

34 D. Cui, J. M. MacLeod, M. Ebrahimi and F. Rosei, CrystEngComm, 2017, 19, 4927-4932.

35 R. Wagia, I. Strashnov, M. W. Anderson and M. P. Attfield, Cryst. Growth Des., 2018, 18, 695-700.

36 C. Hermosa, B. R. Horrocks, J. I. Martínez, F. Liscio, J. Gómez-Herrero and F. Zamora, Chem. Sci., 2015, 6, 2553-2558.

37 A. Dazzi and C. B. Prater, Chem. Rev., 2017, 117, 5146-5173. 38 R. Sakamoto, K. Takada, T. Pal, H. Maeda, T. Kambe and H. Nishihara, Chem. Commun., 2017, 53, 5781-5801.

39 L. Yu, Z.-B. Li and D. Wang, Chem. Commun., 2016, 52, 13771-13774.

40 Y. Hu, N. Goodeal, Y. Chen, A. M. Ganose, R. G. Palgrave, H. Bronstein and M. O. Blunt, Chem. Commun., 2016, 52, 9941-9944. 
41 J.-Y. Yue, X.-H. Liu, B. Sun and D. Wang, Chem. Commun., 2015, 51, 14318-14321.

42 M. El Garah, A. Ciesielski, N. Marets, V. Bulach, M. W. Hosseini and P. Samorì, Chem. Commun., 2014, 50, 12250-12253.

43 Y. Sun, Z. Hu, D. Zhao and K. Zeng, ACS Appl. Mater. Interfaces, 2017, 9, 32202-32210.

44 A. Ciesielski, M. El Garah, S. Masiero and P. Samorì, Small, 2016, 12, 83-95.

45 F. Pu, J. Ren and X. Qu, Chem. Soc. Rev., 2018, 47, 12851306.

46 K. Zhang, G. B. Fahs, M. Aiba, R. B. Moore and T. E. Long, Chem. Commun., 2014, 50, 9145-9148.

47 G. Beobide, O. Castillo, A. Luque and S. P. Yáñez, CrystEngComm, 2015, 17, 3051-3059.

48 R. B. Zerdan, P. Cohn, E. Puodziukynaite, M. B. Baker, M. Voisin, C. Sarun and R. K. Castellano, J. Org. Chem., 2015, 80, 1828-1840.

49 Z. Hua, R. Keogh, Z. Li, T. R. Wilks, G. Chen and R. K. O'Reilly, Macromolecules, 2017, 50, 3662-3670.

50 Q. Lin, X. Zou, G. Zhou, R. Liu, J. Wu, J. Li and W. Duan, Phys. Chem. Chem. Phys., 2011, 13, 12225-12230.

51 M. Sharma, A. Kumarb and P. K. Ahluwalia, RSC Adv., 2016, 6, 60223-60230.

52 J. A. A. W. Elemans, S. Lei and S. D. Feyter, Angew. Chem., Int. Ed., 2009, 48, 7298-7332.

53 D. R. San-Miguel, P. Amo-Ochoaa and F. Zamora, Chem. Commun., 2016, 52, 4113-4127.

54 C. R. Pfeiffer, N. Pearce and N. R. Champness, Chem. Commun., 2016, 52, 11528-11539.

55 J. A. Wytko, R. Ruppert, C. Jeandon and J. Weiss, Chem. Commun., 2018, 54, 1550-1558.

56 K. S. Mali, N. Pearce, S. De Feyter and N. R. Champness, Chem. Soc. Rev., 2017, 46, 2520-2542.

57 R. J. Holmberg and M. Murugesu, J. Mater. Chem. C, 2015, 3, 11986-11998.

58 L. S. Vargas, E. Kim and A. J. Attias, Mater. Horiz., 2017, 4, 570-583.

59 L. P. Xu, Y. Liu and X. Zhang, Nanoscale, 2011, 3, 4901-4915.

60 X. Zhang, Q. Zeng and C. Wang, Nanoscale, 2013, 5, 82698287.

61 J. L. Zhang, S. Zhong, J. Q. Zhong, T. C. Niu, W. P. Hu, A. T. S. Weea and W. Chen, Nanoscale, 2015, 7, 4306-4324.

62 Z. Mu, O. Rubner, M. Bamler, T. Blömker, G. Kehr, G. Erker, A. Heuer, H. Fuchs and L. Chi, Langmuir, 2013, 29, 1073710743.

63 C. Wang, P. K. Jana, H. Zhang, Z. Mu, G. Kehr, T. Blömker, G. Erker, H. Fuchs, A. Heuer and L. Chi, Chem. Commun., 2014, 50, 9192-9195.

64 M. J. Allen, M. Balooch, S. Subbiah, R. J. Tench, R. Balhorn and W. Siekhaus, Ultramicroscopy, 1992, 42, 1049-1053.

65 W. Mamdouh, M. Dong, S. Xu, E. Rauls and F. Besenbacher, J. Am. Chem. Soc., 2006, 128, 13305-13311.

66 J. Freund, M. Edelwirth, P. Kröbel and W. Heckl, Phys. Rev. B: Condens. Matter Mater. Phys., 1997, 55, 5394-5397.
67 W. Mamdouh, D. Mingdong, R. E. A. Kelly, L. N. Kantorovich and F. Besenbacher, J. Phys. Chem. B, 2007, 111, 12048-12052.

68 N. J. Tao and Z. Shi, J. Phys. Chem., 1994, 98, 1464-1471.

69 M. Lukas, R. E. A. Kelly, L. N. Kantorovich, R. Otero, W. Xu, E. Laegsgaard, I. Stensgaard and F. Besenbacher, J. Chem. Phys., 2009, 130, 0247051-0247059.

70 R. E. A. Kelly, W. Xu, M. Lukas, R. Otero, M. Mura, Y. J. Lee, E. Lœgsgaard, I. Stensgaard, L. N. Kantorovich and F. Besenbacher, Small, 2008, 4, 1494-1500.

71 Q. Chen, D. J. Frankel and N. V. Richardson, Langmuir, 2002, 18, 3219-3225.

72 W. Xu, R. E. A. Kelly, R. Otero, M. Schöck, E. Lœgsgaard, I. Stensgaard, L. N. Kantorovich and F. Besenbacher, Small, 2007, 3, 2011-2014.

73 H. Tanaka, T. Nakagawa and T. Kawai, Surf. Sci., 1996, 364, L575-L579.

74 I. Temprano, G. Thomas, S. Haq, M. S. Dyer, E. G. Latter, G. R. Darling, P. Uvdal and R. Raval, J. Chem. Phys., 2015, 142, 101916.

75 S. J. Sowerby, M. Edelwirth and W. M. Heckl, J. Phys. Chem. $B, 1998,102,5914-5922$.

76 A.-M. Chiorcea and A. M. Oliveira-Brett, Bioelectrochemistry, 2002, 55, 63-65.

77 A. Ciesielski, R. Perone, S. Pieraccini, G. P. Spada and P. Samorì, Chem. Commun., 2010, 46, 4493-4495.

78 R. Otero, M. Schöck, L. M. Molina, E. Lœgsgaard, I. Stensgaard, B. Hammer and F. Besenbacher, Angew. Chem., Int. Ed., 2005, 44, 2270-2275.

79 M. Furukawa, H. Tanaka and T. Kawai, J. Chem. Phys., 2001, 115, 3419-3423.

80 Y.-S. Youn, D. H. Kim, H. J. Lee and S. Kim, Chem. Commun., 2015, 51, 12815-12818.

81 R. Otero, M. Lukas, R. E. A. Kelly, W. Xu, E. Lægsgaard, I. Stensgaard, L. N. Kantorovich and F. Besenbacher, Science, 2008, 319, 312-315.

82 M. Iakhnenko, V. Feyer, N. Tsud, O. Plekan, F. Wang, M. Ahmed, O. V. Slobodyanyuk, R. G. Acres, V. Matolín and K. C. Prince, J. Phys. Chem. C, 2013, 117, 18423-18433.

83 S. Xu, M. Dong, E. Rauls, R. Otero, T. R. Linderoth and F. Besenbacher, Nano Lett., 2006, 6, 1434-1438.

84 W. Mamdouh, R. E. A. Kelly, M. Dong, L. N. Kantorovich and F. Besenbacher, J. Am. Chem. Soc., 2008, 130, 695-702. 85 W. Xu, J. G. Wang, M. F. Jacobsen, M. Mura, M. Yu, R. E. A. Kelly, Q. Q. Meng, E. Lægsgaard, I. Stensgaard, T. R. Linderoth, J. Kjems, L. N. Kantorovich, K. V. Gothelf and F. Besenbacher, Angew. Chem., Int. Ed., 2010, 49, 9373-9377.

86 R. Otero, W. Xu, M. Lukas, R. E. A. Kelly, E. Lægsgaard, I. Stensgaard, J. Kjems, L. N. Kantorovich and F. Besenbacher, Angew. Chem., Int. Ed., 2008, 47, 9673-9676. 87 C. Shen, J. R. Cramer, M. F. Jacobsen, L. Liu, S. Zhang, M. Dong, K. V. Gothelf and F. Besenbacher, Chem. Commun., 2013, 49, 508-510.

88 Z. Guo, I. De Cat, B. Van Averbeke, J. Lin, G. Wang, H. Xu, R. Lazzaroni, D. Beljonne, A. P. H. J. Schenning and S. De Feyter, Chem. Commun., 2014, 50, 11903-11906. 
89 A. G. Slater, Y. Hu, L. Yang, S. P. Argent, W. Lewis, M. O. Blunt and N. R. Champness, Chem. Sci., 2015, 6, 1562-1569.

90 S. Cheng, M. Zhang, N. Dixit, R. B. Moore and T. E. Long, Macromolecules, 2012, 45, 805-812.

91 K. Zhang, M. Aiba, G. B. Fahs, A. G. Hudson, W. D. Chiang, R. B. Moore, M. Ueda and T. E. Long, Polym. Chem., 2015, 6, 2434-2444.

92 K. Zhang, M. Chen, K. J. Drummey, S. J. Talley, L. J. Anderson, R. B. Moore and T. E. Long, Polym. Chem., 2016, 7, 6671-6681.

93 I.-H. Lin, C.-C. Cheng, C.-W. Huang, M.-C. Liang, J.-K. Chen, F.-H. Ko, C.-W. Chu, C.-F. Huang and F.-C. Chang, RSC Adv., 2013, 3, 12598-12603.

94 D. González-Rodríguez, P. G. A. Janssen, R. Martín-Rapún, I. De Cat, S. De Feyter, A. P. H. J. Schenning and E. W. Meijer, J. Am. Chem. Soc., 2010, 132, 4710-4719.

95 B. Ilko, W. Sigrid, M. Xiaojing, P. Xie, S. Ramesh, D. Mingdong, W. Chen, M. Wael, W. Jianguo and F. Besenbacher, Phys. Chem. Chem. Phys., 2010, 12, 36163621.

96 C. J. Serpell, M. Barłóg, K. Basu, J. F. Fakhoury, H. S. Bazzi and H. F. Sleiman, Mater. Horiz., 2014, 1, 348-354.

97 P. Singh, S. Campidelli, S. Giordani, D. Bonifazi, A. Bianco and M. Prato, Chem. Soc. Rev., 2009, 38, 2214.

98 N. Karousis, N. Tagmatarchis and D. Tasis, Chem. Rev., 2010, 110, 5366-5397.

99 C. Farrera, F. Torres Andón and N. Feliu, ACS Nano, 2017, 11, 10637-10643.

100 R. Alshehri, A. M. Ilyas, A. Hasan, A. Arnaout, F. Ahmed and A. Memic, J. Med. Chem., 2016, 59, 8149-8167.

101 E. Heister, E. W. Brunner, G. R. Dieckmann, I. Jurewicz and A. B. Dalton, ACS Appl. Mater. Interfaces, 2013, 5, 1870-1891.

102 J. M. Schnorr and T. M. Swager, Chem. Mater., 2011, 23, 646-657.

103 R. Soleyman, S. Hirbod and M. Adeli, Biomater. Sci., 2015, 3, 695-711.

104 M. Adeli, R. Soleyman, Z. Beiranvand and F. Madani, Chem. Soc. Rev., 2013, 42, 5231.

105 A. Bianco, K. Kostarelos, C. D. Partidos and M. Prato, Chem. Commun., 2005, 571-577.

106 K. V. Singh, R. R. Pandey, X. Wang, R. Lake, C. S. Ozkan, K. Wang and M. Ozkan, Carbon, 2006, 44, 1730-1739.

107 C. Dwyer, M. Guthold, M. Falvo, S. Washburn, R. Superfine and D. Erie, Nanotechnology, 2002, 13, 601-604.

108 P. Singh, V. Venkatesh, N. Nagapradeep, S. Verma and A. Bianco, Nanoscale, 2012, 4, 1972-1974.
109 P. Singh, J. Kumar, F. M. Toma, J. Raya, M. Prato, B. Fabre, S. Verma and A. Bianco, J. Am. Chem. Soc., 2009, 131, 1355513562.

110 P. Singh, G. Lamanna, C. Ménard-Moyon, F. M. Toma, E. Magnano, F. Bondino, M. Prato, S. Verma and A. Bianco, Angew. Chem., Int. Ed., 2011, 50, 9893-9897.

111 P. Singh, F. M. Toma, J. Kumar, V. Venkatesh, J. Raya, M. Prato, S. Verma and A. Bianco, Chem.-Eur. J., 2011, 17, 6772-6780.

112 P. Singh, C. Ménard-Moyon, A. Battigelli, F. M. Toma, J. Raya, J. Kumar, N. Nidamanuri, S. Verma and A. Bianco, Chem.-Asian J., 2013, 8, 1472-1481.

113 P. Singh, C. Ménard-Moyon, J. Kumar, B. Fabre, S. Verma and A. Bianco, Carbon, 2012, 50, 3170-3177.

114 M. Quintana and M. Prato, Chem. Commun., 2009, 60056007.

115 M. Quintana, H. Traboulsi, A. Llanes-Pallas, R. Marega, D. Bonifazi and M. Prato, ACS Nano, 2012, 6, 23-31.

116 B. Mohapatra, P. Pratibha and S. Verma, Chem. Commun., 2017, 53, 4748-4758.

117 C. S. Purohit and S. Verma, J. Am. Chem. Soc., 2006, 128, 400-401.

118 C. S. Purohit and S. Verma, J. Am. Chem. Soc., 2007, 129, 3488-3489.

119 A. K. Mishra, C. S. Purohit, J. Kumar and S. Verma, Inorg. Chim. Acta, 2009, 362, 855-860.

120 R. K. Saravanan, P. Saha, V. Venkatesh, T. G. Gopakumar and S. Verma, Inorg. Chem., 2017, 56, 3976-3982.

121 J. Gómez-Herrero and F. Zamora, Adv. Mater., 2011, 23, 5311-5317.

122 R. Mas-Ballesté, J. Gómez-Herrero and F. Zamora, Chem. Soc. Rev., 2010, 39, 4220.

123 J. V. Barth, G. Costantini and K. Kern, Nature, 2005, 437, 671-679.

124 V. Venkatesh, P. Pachfule, R. Banerjee and S. Verma, Chem.-Eur. J., 2014, 20, 12262-12268.

125 S. Mandal, C. Wang, R. K. Prajapati, J. Kösters, S. Verma, L. Chi and J. Müller, Inorg. Chem., 2016, 55, 7041-7050.

126 M. El Garah, S. Sinn, A. Dianat, A. Santana-Bonilla, R. Gutierrez, L. De Cola, G. Cuniberti, A. Ciesielski and P. Samori, Chem. Commun., 2016, 52, 11163-11166.

127 P. Amo-Ochoa, M. I. Rodríguez-Tapiador, O. Castillo, D. Olea, A. Guijarro, S. S. Alexandre, J. Gómez-Herrero and F. Zamora, Inorg. Chem., 2006, 45, 7642-7650.

128 G. Vegas, R. Lorca, A. Latorre, K. Hassanein, J. G. Carlos, O. Castillo, F. Zamora and P. Amo-Ochoa, Angew. Chem., Int. Ed., 2017, 56, 987-991. 